\title{
Genetic Causes and Modifiers of Autism Spectrum Disorder
}

\author{
Lauren Rylaarsdam and Alicia Guemez-Gamboa* \\ Department of Physiology, Feinberg School of Medicine, Northwestern University, Chicago, IL, United States
}

Autism Spectrum Disorder (ASD) is one of the most prevalent neurodevelopmental disorders, affecting an estimated 1 in 59 children. ASD is highly genetically heterogeneous and may be caused by both inheritable and de novo gene variations. In the past decade, hundreds of genes have been identified that contribute to the serious deficits in communication, social cognition, and behavior that patients often experience. However, these only account for $10-20 \%$ of ASD cases, and patients with similar pathogenic variants may be diagnosed on very different levels of the spectrum. In this review, we will describe the genetic landscape of ASD and discuss how genetic modifiers such as copy number variation, single nucleotide polymorphisms, and epigenetic alterations likely play a key role in modulating the phenotypic spectrum of ASD patients. We also consider how genetic modifiers can alter convergent signaling

OPEN ACCESS

Edited by: João Peça,

University of Coimbra, Portugal

Reviewed by:

Santhosh Girirajan,

The Pennsylvania State University,

United States

Chihiro Sato,

Nagoya University, Japan

*Correspondence:

Alicia Guemez-Gamboa

alicia.guemez@northwestern.edu

Specialty section:

This article was submitted to

Cellular Neuropathology,

a section of the journal

Frontiers in Cellular Neuroscience

Received: 07 May 2019

Accepted: 06 August 2019

Published: 20 August 2019

Citation:

Rylaarsdam $L$ and

Guemez-Gamboa A (2019) Genetic

Causes and Modifiers of Autism

Spectrum Disorder.

Front. Cell. Neurosci. 13:385.

doi: 10.3389/fncel.2019.00385 pathways and lead to impaired neural circuitry formation. Lastly, we review sex-linked modifiers and clinical implications. Further understanding of these mechanisms is crucial for both comprehending ASD and for developing novel therapies.

Keywords: autism spectrum disorder, genetic modifiers, CNV, epigenetics, gene-environment interaction

\section{INTRODUCTION}

Autism was first described by Kanner (1943) in a detailed report of 11 children with similar unusual tendencies. Intriguing common symptoms such as improper facilitation of language, indifference to other people, and obsessive interests can clearly be discerned while reading Kanner's thorough patient history. Twenty-three years later, the first epidemiological study of autism estimated prevalence to be 4.5 per 10,000 individuals. Estimates have since increased drastically to 1 in 59 individuals affected, with at least three times as many males diagnosed as females (Loomes et al., 2017). This significant increase in prevalence is partially attributable to both increase in awareness and evolvement of Diagnostic and Statistical Manual of Mental Disorders (DSM) criteria, from a childhood form of schizophrenia in 1952, to a core diagnosis covering a spectrum of disorders in the present (Zeldovich, 2018). The changing landscape of factors required for diagnosis makes it difficult to quantify the actual increase in prevalence.

According to the current DSM-5 criteria, only two core features make up an autism spectrum disorder (ASD) diagnosis: (1) persistent deficits in social communication and social interaction across multiple contexts; and (2) restricted, repetitive patterns of behavior, interests, or activities (Lai et al., 2014). Because of the broad nature of these definitions, an ASD diagnosis often co-occurs with other conditions. Motor abnormalities (79\%), gastrointestinal problems (up to 70\%), epilepsy (up to $30 \%$ ), intellectual disability (45\%), and sleep disorders (50-80\%) are common examples (Lai et al., 2014). Language disorders are frequently co-occurring and were even included in the DSM-IV criteria. 
Since autism's identification as a diagnosis, the medical and scientific community have put immense effort into determining the risk factors and etiology. In Kanner's original assessment, he makes the unfortunate observation that in addition to patients having highly intelligent parents, "One other fact stands out prominently. In the whole group, there are very few really warmhearted fathers and mothers" (Kanner, 1943). Thankfully, this "Refrigerator Mother" theory of autism was quickly disproved. ASD is now understood to be a disease of complex interaction between genetics and the environment, with heritability estimates ranging from 40 to $80 \%$ (Chaste and Leboyer, 2012). Extensive genetic studies have revealed hundreds of genes linked to autism. Epidemiological investigations have begun to elucidate which environmental factors might be contributing to risk, but there is a lot left to understand about how they interact with genetic predisposition to contribute to ASD etiology.

As is often the case with complex diseases, individuals with similar pathogenic variants may have drastically varying phenotypes. For example, people with duplications of proximal $15 q$ range from unaffected to severely disabled (Cook et al., 1997; Bolton et al., 2001). Genetic modifiers - factors that modulate the expression of other genes - likely exist when individuals with the same pathogenic variant present on opposite ends of the spectrum. In this review, we will discuss what is presently known about the genetic landscape of ASD, then look at potential modifiers including copy number variation (CNV), double-hit mutations, epigenetic influences, and sex-linked effects.

\section{GENETICS OF ASD}

\section{Identification of Candidate ASD Risk Genes}

Following the classification of autism by Kanner, research efforts were undertaken to determine the disease etiology. Though it was initially assumed to be of environmental origin, an improved understanding of the role of genetics in human health soon suggested otherwise. In 1977, Folstein and Rutter (1977) conducted twin studies upon the observation that incidence among siblings was $50 \times$ higher than average. They found that monozygotic twins were more likely to share a diagnosis than dizygotic twins, suggesting a genetic influence. Bailey et al. (1995) supported this finding, documenting 60\% concordance for monozygotic twins versus no concordant dizygotic pairs. In addition, risk of a child having ASD was found to be proportional to the percentage of the genome they shared with an affected sibling or parent (Constantino et al., 2010; Risch et al., 2014; Sandin et al., 2014). By the turn of the century, ASD was established to have some genetic component, though which genes were involved remained a mystery.

Early karyotype studies documenting chromosomal abnormalities began to shed light on which regions of the genome were involved (Gillberg and Wahlström, 1985). Additional susceptibility loci screens implicated regions on chromosome 7q, 1p, 3q, 16p, and 15q (IMGSAC, 1998; Barrett et al., 1999; Buxbaum et al., 2001; International Molecular Genetic Study of
Autism Consortium [IMGSAC], 2001; Liu et al., 2001; Auranen et al., 2002; Lamb et al., 2002; Shao et al., 2003; Risch et al., 2014). However, to investigate at gene-level resolution, early studies had to use the candidate approach. Hypothesized targets included genes from suspected chromosomal regions that played a critical role in neurodevelopment, such as homeobox (Hox) family or Wnt genes. Unsurprisingly, many early studies using this method were largely inconclusive (Krebs et al., 2002; Lamb et al., 2002; Talebizadeh et al., 2002; Zhang et al., 2002). Starting in 2001, the candidate approach experienced moderate success with findings supporting reelin $(R E L N)$, aristaless related homeobox $(A r x)$, methyl-CpG binding protein 2 (MeCP2), neuroligin 3 (NLGN3), neuroligin 4 (NLGN4), tuberous sclerosis complex 2 (TSC2), and ubiquitin protein ligase E3A (UBE3A)'s involvement in ASD etiology (Persico et al., 2001; Strømme et al., 2002; Carney et al., 2003; Jamain et al., 2003; Serajee et al., 2003; Jiang et al., 2004).

In the early 2000s, the advent of high throughput sequencing revolutionized genetic research and enabled investigators to study ASD on a genome-wide level. Sequencing technology quickly confirmed that the etiology of ASD was multigenic and highly heterogeneous, with very few of the same pathogenic variants present in a significant percentage of afflicted individuals. It is now known that the average case is a product of many susceptibility-increasing variations. Only a handful of ASD-related diseases have monogenic causes, such as Rett syndrome, fragile $\mathrm{X}$ syndrome, tuberous sclerosis, and SchuursHoeijmakers syndrome (Artuso et al., 2011; Stern et al., 2017; Woodbury-Smith and Scherer, 2018). Dozens of large-scale genetic studies have since been conducted on ASD patients and their families, leading to hundreds of risk genes being identified. While these proteins have diverse functions, a majority of reproducible hits come from two broad classes of proteins: those involved in synapse formation, and those involved in transcriptional regulation and chromatin-remodeling pathways (De Rubeis et al., 2014).

Synapse-related risk genes include those encoding celladhesion proteins such as neuroligins, neurexins, and cadherins; synaptic vesicle cycling proteins synapsin-1 (SYN1) and synapsin-2 (SYN2); ion transport proteins such as sodium voltage-gated channel alpha subunit 2 (SCN2A), calcium voltage-gated channel subunit alpha1 E (CACNA1E), calcium voltage-gated channel auxiliary subunit beta 2 (CACNB2), potassium voltage-gated channel subfamily Q members 3 and 5 (KCNQ3 and KCNQ5), potassium voltagegated channel subfamily D member 2 (KCND2), glutamate receptor signaling protein $\mathrm{SH} 3$ and multiple ankyrin repeat domains 3 (SHANK3), synaptic Ras GTPase activating protein 1 (SYNGAP1), and gamma-aminobutyric acid type A receptor gamma3 subunit (GABRG3) (Jamain et al., 2003; Durand et al., 2012; Schmunk and Gargus, 2013; Giovedí et al., 2014; Stessman et al., 2017). In vivo data supports the implication of synapse pathology and abnormal neural network formation in ASD.

Additional susceptibility loci impact transcription of other proteins through various mechanisms. For example, multiple studies have found an increased de novo mutation load in regulatory elements of ASD risk genes in patients 
(Turner et al., 2016, 2017; Short et al., 2018). The broad class of susceptibility genes that impacts transcription and chromatinremodeling pathways includes $M e C P 2, U B E 3 A$, chromodomain helicase DNA binding protein 8 (CHD8), activity dependent neuroprotector homeobox ( $A D N P$ ), pogo transposable element derived with ZNF domain (POGZ), fragile X mental retardation protein (FMRP), and RNA binding forkhead box (RBFOX) genes (Carney et al., 2003, p. 2; Samaco et al., 2005; De Rubeis et al., 2014; Stessman et al., 2017; Tran et al., 2019). These pathogenic variants have the potential to induce extremely widespread effects. For example, Tran et al. (2019) recently showed that $F M R P$ and fragile $\mathrm{X}$ related protein 1 (FXRP1) mutations can result in abnormal RNA-editing enzyme activity, resulting in a global bias for adenosine-to-inosine hypoediting in ASD brains. Diverse phenotypes that may result are further discussed in the epigenetics section.

\section{Somatic Mosaicism and ASD Risk}

Disease-causing variations were conventionally thought to be familial/inherited and present in every cell in the body. However, the role of somatic mosaicism, which is the result of a post-zygotic DNA mutation, is increasingly being recognized as crucial to various neurodevelopmental diseases including autism (Poduri et al., 2013; Ronemus et al., 2014; D'Gama and Walsh, 2018). During neurogenesis, each progenitor gives rise to roughly five single nucleotide variants (SNV) per day as the brain rapidly develops (Bae et al., 2018; D'Gama and Walsh, 2018). Studies estimate that of de novo pathogenic variations, roughly $5-7 \%$ are postzygotic, though estimates of up to $22 \%$ have been reported (Acuna-Hidalgo et al., 2015; Freed and Pevsner, 2016; Krupp et al., 2017; Lim et al., 2017). Most mutations are harmless, but variations in exons can be extremely detrimental. Pathogenic somatic variations have been connected to ASD, Rett syndrome, tuberous sclerosis, intellectual disability, schizophrenia, and many other disorders (Clayton-Smith et al., 2000; Bourdon et al., 2001; Qin et al., 2010; Gilissen et al., 2014; AcunaHidalgo et al., 2015; Tyburczy et al., 2015; Freed and Pevsner, 2016; Dou et al., 2017; Doyle et al., 2017; Krupp et al., 2017; D'Gama and Walsh, 2018).

Until recently, our understanding of somatic mosaicism in ASD was restricted primarily to case reports (Oliveira et al., 2003; Sauter et al., 2003; Papanikolaou et al., 2006; Havlovicova et al., 2007; Yurov et al., 2007; Castermans et al., 2008; Kakinuma et al., 2008; Vorstman et al., 2011). Several recent investigations of whole exome-sequencing (WES) data from large cohorts have been instrumental in shaping our understanding of the role of somatic mosaicism, which is currently estimated to account for roughly $3-5 \%$ of simplex ASD cases (Freed and Pevsner, 2016; Krupp et al., 2017). Lim et al. (2017) used WES analysis of 5,947 ASD-affected families and determined that somatic variations in autistic individuals were more likely to be in critical exons than variations in control siblings. Interestingly, they found that the pathogenic variants had enhanced expression in the amygdala, an area critical for emotional response and social awareness (Rasia-Filho et al., 2000). In another large WES study, new risk genes identified were enriched in the cerebellum, which suggests potential coordination difficulty that could be related to gait disorders common in autistic children (Dou et al., 2017). Freed and Pevsner (2016) analyzed 2,388 families and identified an ascertainment bias for pathogenic mosaic variations in ASD individuals relative to unaffected siblings. These large-scale sequencing studies of post-zygotic mutations have both confirmed previously implicated candidate genes, such as $S C N 2 A$, in addition to revealing dozens of new risk genes and establishing somatic mosaicism as a significant factor in ASD etiology (Lim et al., 2017).

\section{CNVs Contribute to ASD Susceptibility}

Copy number variations (CNVs) are submicroscopic structural variants in chromosomes that include duplications, deletions, translocations, and inversions, sometimes stretching several kilobases (Marshall et al., 2008). CNV can either be inherited or arise de novo (Thapar and Cooper, 2013). Many genes may be affected with these changes, but not all are necessarily drivers of disease. Studies have found a higher load of rare, genic CNVs in autistic individuals, implicating these variants in ASD pathology (Sebat et al., 2007; Pinto et al., 2010; Pizzo et al., 2019). $\mathrm{CNV}$ is now understood as an extremely important contributing factor in ASD susceptibility, and current estimates postulate that these variations directly cause roughly $10 \%$ of ASD cases (Geschwind, 2011).

Studies of how individual CNVs contribute to ASD have been done for more frequent structural variants, such as $16 \mathrm{p} 11.2$ duplications. The majority of the 25 genes in this region are highly active during nervous system development and are critical for proper formation (Blaker-Lee et al., 2012). While the alteration of many genes involved in development suggests a mechanism for the diverse symptoms observed in ASD, Golzio et al. (2012) reported that only one gene in the 16p11.2 region, potassium channel tetramerization domain containing 13 (KCTD13), seems to be the major driver for neuropsychiatric disease. Duplications or deletions of this gene are thought to affect synaptic transmission through altered regulation of Ras homolog family member A (RHOA) (Escamilla et al., 2017). However, Escamilla et al. (2017) also hypothesized that KCTD13 deletions alone are not likely to be sufficient for disease. Mouse models suggest another gene in the $16 \mathrm{p} 11.2$ region as a driver of disease - mitogen-activated protein kinase 3 (MAP3) with deletions resulting in altered cortical cytoarchitecture and reduced brain size (Pucilowska et al., 2015). Likely, the real driver of disease in 16p11.2 duplications or deletions is not from just one gene, but an interaction of all 25 contributing to susceptibility. Iyer et al. (2018) systematically investigated interaction between genes in the 16p11.2 region, using RNAi in Drosophila to test 565 pairwise knockdowns. In addition to 24 modifying interactions discovered between pairs of genes within the 16p11.2 region, they also found 46 interactions between 16p11.2 genes and others involved in neurodevelopment (Iyer et al., 2018). This strongly suggests that modifying interactions within CNVs result in the complex phenotypes observed and may not be elucidated from studies with single genes, a phenomenon that is likely true for other $\mathrm{CNV}$ regions in addition to $16 \mathrm{p} 11.2$.

The disease mechanisms of other CNVs are less frequently studied due to the paucity of commonly affected regions. Even the 
most prevalent ASD-associated CNVs, such as $15 \mathrm{q} 11-13$ as well as 16 p 11.2 , are only present in roughly $1 \%$ of autism cases (Kumar et al., 2008; Marshall et al., 2008; Weiss et al., 2008; Marshall and Scherer, 2012). In addition, there are no known CNVs with complete penetrance; studies that find CNVs with significant correlation to ASD often detect non-ASD carriers, or ASD siblings without the variant (Marshall et al., 2008). One useful approach in the midst of this heterogeneity is to assess common functional networks affected. Repeatedly, studies have shown that autistic individuals have deletions in synaptic genes, such as SHANK3, dipeptidyl peptidase-like 10 (DPP10), neuroligins, and neurexins (The Autism Genome Project Consortium et al., 2007; Marshall et al., 2008; Glessner et al., 2009; Pinto et al., 2010, 2014; Marshall and Scherer, 2012). Other common functional gene sets with rare CNVs include those involved in cell proliferation and development, chromatin regulation, and ubiquitin pathways (Glessner et al., 2009; Pinto et al., 2010, 2014).

With certain CNVs, copy number dosage appears to affect disease phenotype. For example, Horev et al. (2011) observed a dose-dependent effect and change in brain structure in mice with 16p11.2 deletions and duplications, but this effect is not as established in humans (Kumar et al., 2008). Another study investigating $\mathrm{CNV}$ in the locus containing the UBE3A gene also report a positive correlation between duplication and autistic traits in mice, as well as decreased glutamatergic synaptic transmission (Smith et al., 2011). In humans, Stefansson et al. (2014) analyzed a 15q11.2 CNV region of autistic individuals and found two brain areas with dose-dependent structural and functional effects. Interestingly, some non-ASD/schizophrenic controls who were diagnosed with dyslexia and dystaxia also exhibited the same structural changes (Stefansson et al., 2014). In another study with humans, Girirajan et al. (2013) reported a dose-dependent effect from their microarray analysis with identified CNVs in ASD-associated genes, finding a positive correlation between duplication size increase and autism severity increase, but no correlation between duplication size and non-verbal IQ. $\mathrm{CNV}$ are often critical and complex contributors to ASD risk, but patients with similar structural variants may have highly variable phenotypes. Following sections will discuss how non-causative modifiers play an important role in modulating CNV pathogenicity.

\section{Epigenetic Regulation and ASD}

Genes with epigenetic-modulating functions are highly involved in ASD susceptibility. A recent review of 215 candidate genes estimated that $19.5 \%$ are epigenetic regulators, suggesting the potential for diverse disease phenotypes from few pathogenic variants (Duffney et al., 2018). Another study suggested that risk genes with high penetrance were typically located in the nucleus and involved in modulation of expression, or tied to the protein-protein interaction network essential in guiding CNS developmental patterning (Casanova et al., 2016). Twin studies particularly demonstrate the profound ways epigenetics can modulate disease phenotype; for example, a study of 50 pairs of monozygotic twins discordant for ASD reported numerous autism-associated differentially methylated regions, with methylation patterns at some $\mathrm{CpG}$ sites common to symptom groups (Wong et al., 2014).

Though the scientific and medical community still has a great deal to learn about epigenetic modulation of ASD, patterns have emerged from large-scale epigenomic studies. Susceptibility loci often include genes involved in methylation such as KMT2C, lysine methyltransferase 5B (KMT5B), and lysine demethylase 6B (KDM6B); chromatin remodeling proteins including MeCP2, CHD8, and POGZ; RNA-binding/splicing proteins such as FMRP and the RBFOX family, post-translational modification proteins like UBE3A, mindbomb E3 ubiquitin protein ligase 1 (MIB1); or transcription factors like ADNP and additional sex combs like 3 (ASXL3) (De Rubeis et al., 2014). Targets of these proteins can range from few to hundreds, and often include pathways previously implicated in autism, such as synaptic formation. To demonstrate how mutations in a single epigenetic regulator can modify many other risk genes, we will look more in depth at two key susceptibility genes: $M e C P 2$ and $U B E 3 A$.

$\mathrm{MeCP} 2$ is a chromatin modifier that is consistently implicated in ASD. In a healthy individual, the binding action of $\mathrm{MeCP} 2$ has been shown to regulate many genes with synaptic function, such as $G A B R B 3$, brain derived neurotrophic factor (BDNF), distal-less homeobox 5 ( DLX5), insulin like growth factor binding protein 3 (IGFBP3), cyclin dependent kinase like 1 (CDKL1), protocadherin beta 1 (PCDHB1), protocadherin 7 (PCDH7), and lin-7 homolog A (LIN7A) (Samaco et al., 2005; Kubota and Mochizuki, 2016). It also serves post-translational functions (Cheng and Qiu, 2014). In addition, MeCP2 is the rate-limiting factor in regulating glutamatergic synapse formation during development, which implicates its involvement in yet another important aspect of ASD pathology (Chao et al., 2007). MeCP2 is shown to be reduced in the frontal cortex of ASD individuals due to increased methylation of its promoter (Samaco et al., 2005; Nagarajan et al., 2006, 2008).

UBE3A, an E3 ubiquitin protein ligase, is a second important epigenetic regulator strongly implicated in ASD pathology. It is modulated by $\mathrm{MeCP} 2$, but can be causative on its own (Samaco et al., 2005, p. 2). UBE3A lies in the chromosomal region 15q1113 , which is commonly duplicated in autism. Dose-dependent effects have been positively correlated with reduced excitatory synaptic transmission, delay of first word, and psychomotor regression (Guffanti et al., 2011; Smith et al., 2011; Xu et al., 2018). The mechanism of UBE3A's pathological activity can be hypothesized based on its function as a ubiquitin ligase, which targets proteins for degradation, but research is still revealing exactly how these dose-dependent impairments occur. Lee et al. (2014) identified four proteosome-related proteins that were direct substrates of UBE3A. Overexpression of UBE3A and one of its substrates, proteasome $26 \mathrm{~S}$ subunit, non-ATPase 4 (Rpn10), led to increased accumulation of ubiquitinated proteins, suggesting a proteostatic imbalance. Proteosome health has been strongly implicated in dendritic spine outgrowth, linking UBE3A with one of the key pathologies observed in autism (Hamilton et al., 2012; Puram et al., 2013). Its involvement in Wnt signaling could also cause significant perturbation during development (Yi et al., 2017). $M e C P 2$ and $U B E 3 A$ are just two examples of how one altered gene can have extremely far-reaching effects. 
Large-scale epigenetic studies have also helped achieve a broader picture of epigenetic mis-regulation in ASD. Sun et al. (2016) conducted a histone acetylome-wide association study on 257 post-mortem prefrontal and temporal cortex samples. Surprisingly, they found that $>68 \%$ of both syndromic and idiopathic cases shared a common acetylome signature at roughly 5,000 enhancer regions (Sun et al., 2016). Intriguingly, a SHANK3 mouse model of autism displayed rescued behavioral phenotypes when treated with a potent histone deacetylase inhibitor, reinforcing the role of epigenetics in ASD (Qin et al., 2018). Ladd-Acosta and coworkers measured over 485,000 CpG loci in post-mortem brain tissue from 40 individuals and identified four differentially methylated regions. Three sites were found in cortical tissue: the proline rich transmembrane protein 1 (PRRT1) 3' UTR, promoter regions of tetraspanin 32 (TSPAN32), and C11orf21. The last site, an alternative promoter for succinate dehydrogenase complex flavoprotein subunit A pseudogene 3 (SDHAP3), was found in cerebellar tissue (Ladd-Acosta et al., 2014). Affected pathways implied in these studies and others include synaptic transmission, immune function, ion transport, and GABAergic genes (Nardone and Elliott, 2016; Sun et al., 2016; Andrews et al., 2017; Zhubi et al., 2017).

Mor et al. (2015) took a different approach, using small RNA sequencing data and correlating results to genome-wide DNA methylation data to find dysregulated miRNAs. miRNAs that were found to be significantly expressed in the ASD brain were linked to synaptic function, consistent with data from numerous other studies. They also discovered a link to the oxytocin receptor $(O X T R)$ gene, suggesting attenuated OXTR expression in the autistic brain. This finding was supported by a study that found fetal membranes from preterm birth had hypermethylated OXTR, potentially linking an environmental risk factor to a pathological mechanism (Behnia et al., 2015). Another risk gene with epigenetic functions is engrailed homeobox 2 (EN2), a homeobox gene with an unusual methylation pattern in ASD that has been hypothesized to cause abnormal cerebellar Purkinje growth (James et al., 2013). The list of ASD risk genes with epigenetic functions is vast, suggesting a mechanism by which few mutations can result in widespread misregulation of gene expression. Because of this, genes with epigenetic functions and their substrates may be promising targets of therapies. For example, mutations in $F M R P$, a chromatin remodeler, result in widespread gene expression abnormalities, but a recent study found that inhibition of FMRP target bromodomain containing 4 (BRD4) alleviated many of the disease characteristics (Korb et al., 2017). Proteins with epigenetic-regulating function may also be key targets of disease modifiers, a concept that will be discussed later in this review.

\section{ASD Risk Genes Overlap With Other Diseases}

Large-scale sequencing studies of major psychiatric diseases have revealed extensive overlap in risk loci, challenging the classification of these conditions as distinctive disorders. In 2013, the Cross-Disorder Group of the Psychiatric Genomics Consortium (PGC) conducted a massive study with 33,332 cases and 27,888 controls in order to identify pathogenic variants shared between ASD, schizophrenia, bipolar disorder, ADHD, and major depressive disorder (Cross-Disorder Group of the Psychiatric Genomics Consortium, 2013; Cross-Disorder Group of the Psychiatric Genomics Consortium et al., 2013). In addition to establishing varying degrees of pair-wise crossover, they found loci that reached genome-wide significance for all five disorders near the following genes: inter-alpha-trypsin inhibitor heavy chain 3 (ITIH3), arsenite methyltransferase (AS3MT), calcium voltage-gated channel subunit alpha1 C (CACNA1C), and CACNB2. Glessner et al. (2017) have also conducted a large-scale meta-analysis of structural variants across the same diseases and correlated structural variants in the loci of dedicator of cytokinesis 8 (DOCK8) and $\mathrm{KN}$ motif and ankyrin repeat domains 1 (KANK1) with all five conditions. Schork et al. (2019) recently hypothesized that abnormal gene regulation in radial glia and interneurons during mid-gestation is a mechanism of shared risk, after using GWAS to identify susceptibility loci in genes including phosphodiesterase 1A (PDE1A), protein phosphatase 1 regulatory inhibitor subunit 1C (PPP1R1C), RHOA, immunoglobulin superfamily member 11 (IGSF11), and sortilin related VPS10 domain containing receptor 3 (SORC3).

Studies also report shared susceptibility genes across a more restricted set of psychiatric diseases. For example, ASD, intellectual disability (ID), and schizophrenia have been found to share risk loci in FMRP targets, CHD5, CHD8, SCN2A, and neurexin 1 (NRXN1) (Iossifov et al., 2014; Wang et al., 2019). Wang et al. (2019) also found commonalities across ASD, ID, and bipolar disorder with increased incidence of de novo pathogenic variants in periodic circadian regulator 1 (PER1) and lysine methyltransferase 2C (KMT2C). Khanzada et al. (2017) found 23 susceptibility genes common to ASD, bipolar disorder, and schizophrenia including dopamine receptor D2 (DRD2), cholinergic receptor nicotinic alpha 7 subunit (CHRNA7), 5-hydroxytryptamine receptor 2A (HTR2A), solute carrier family 6 member 3 (SLC6A3), and tryptophan hydroxylase 2 (TPH2). Hit genes were primarily involved in dopamine and serotonin homeostasis, suggesting a potential mechanism for abnormal emotional regulation observed across all three disorders (Khanzada et al., 2017). The immense crossover revealed in these studies intriguingly suggests some level of shared etiology across psychiatric conditions, despite having clinically distinct presentations.

Of the four other diseases assessed in the PGC study, the most highly correlated disease to ASD was schizophrenia (Cross-Disorder Group of the Psychiatric Genomics Consortium et al., 2013). Previous epidemiological studies had suggested their linkage, reporting increased risk of ASD in children with schizophrenic parents and significant co-morbidity of childonset schizophrenia and autism (Rapoport et al., 2009; Sullivan et al., 2012). A follow-up report to the 2013 PGC study estimated genetic correlation between the two diseases to be $23 \%$, with shared risk loci including several genes involved in neurodevelopment, such as forkhead box P1 (FOXP1), exostosin glycosyltransferase 1 (EXT1), astrotactin 2 (ASTN2), monoADP ribosylase 2 (MACROD2), and histone deacetylase 4 
(HDAC4) (The Autism Spectrum Disorders Working Group of The Psychiatric Genomics Consortium, 2017). In addition to susceptibility genes involved in neurodevelopment, other studies have also reported shared susceptibility in genes affecting chromatin remodeling, oxidative stress response, and lipid metabolism (McCarthy et al., 2014; Lim et al., 2017).

Many studies have also found a significant correlation between autistic and ADHD scored traits. This includes a study of autistic symptoms in ADHD probands and siblings, autistic trait correlation in an ADHD twin sample, and an association between autistic and ADHD traits in the general population (Reiersen et al., 2007; Ronald et al., 2008; Mulligan et al., 2009; Stergiakouli et al., 2017). Nijmeijer et al. (2010) identified five specific genetic loci that were associated with ASD traits in children with ADHD: $7 \mathrm{q} 36,16 \mathrm{p} 13,18 \mathrm{p} 11,15 \mathrm{q} 24$, and 12q24. A study investigating the overlap of pathological structural variants in ADHD and ASD found significant overlap in genes related to a wide variety of processes, including the nicotinic receptor signaling pathway and cell division (Martin et al., 2014). The shared heritability of ASD and ADHD is still being explored, and is further discussed in a review by Rommelse et al. (2010).

Since ASD is a multigenic and highly heterogeneous disease that often co-occurs with other conditions, it can be difficult to distinguish which genes truly have overlapping risk for multiple psychiatric conditions, and which variations are responsible for the common disease phenotypes. For example, the ubiquitin ligase gene UBE3A is implicated in both autism and Angelman Syndrome, a condition distinct from ASD but with similar symptoms, such as movement and speech defects. Interestingly, Angelman Syndrome is generally associated with UBE3A deletions, while ASD can be caused by duplications - yet the same individual can be diagnosed with both syndromes (Peters et al., 2004; Williams et al., 2010; Smith et al., 2011; Kalsner and Chamberlain, 2015; Yi et al., 2015). Another example is intellectual disability, which co-occurs with autism in roughly $45 \%$ of cases (Lai et al., 2014). Multiple studies have found that ASD and intellectual disability share risk loci (Pinto et al., 2010; McCarthy et al., 2014), but overlapping phenotypes are a potentially confounding factor. Similarly, other risk genes for ASD are epigenetic regulators whose effectors are associated with different diseases (Samaco et al., 2005; Pinto et al., 2010; Michaelson et al., 2017). The interaction and overlap between psychiatric disorders is complex, and much is left to discern regarding shared disease mechanisms.

\section{MODIFIERS IN ASD}

\section{Genetic Modifiers}

Though significant progress has been made in determining genetic causes of ASD, many aspects of how pathogenic variants regulate genetic susceptibility remain unknown. Individuals with the same variants can have widely heterogeneous disease presentations and levels of disability. Presence of second modulating variants that may interact with other susceptibility loci are one possible explanation of this heterogeneity. This "second hit" could be somatic - a phenomenon first proposed to cause disease by Alfred Knudson in the context of retinoblastomas - or in the germline, a "two-locus model" previously explored in conditions such as Hirschprung disease (Knudson, 1971; Fisher and Scambler, 1994; McCallion et al., 2003). To date, genetic evidence supporting a multiplex theory of autism has primarily been found for germline second-hits. Studies with CNVs will be discussed first, followed by a brief overview of known modulating SNPs. These investigations of how non-causative variants may modify the ASD phenotype are challenging to undertake, as few autistic individuals have the same pathogenic variants. In addition, there is not yet a complete understanding of which CNVs and SNPs are pathogenic in ASD.

One way to circumvent these issues is to investigate an autism subtype with a monogenic cause, such as Rett Syndrome. Artuso et al. (2011) used this strategy and identified 15 "likely" and 14 "unlikely" modulators of the RTT phenotype based on array comparative genome hybridization with eight RTT subjects. Another valuable approach is to assess monozygotic twins with a discordant phenotype. Several studies have assessed potential differences in CNVs or epigenetic regulation in discordant monozygotic twins, revealing potential methylation pattern differences in one case and anomalies in the 2p25.3 region in another (Bruder et al., 2008; Kunio et al., 2013; Rio et al., 2013). However, a study involving 100 twin pairs failed to find differences in CNVs that could explain the discordant phenotypes (Stamouli et al., 2018). The authors still acknowledge postzygotic mosaicism as a potential modifier and encourage more studies to help develop a clearer understanding of CNV modulating activity.

A handful of reports also exist of putative modifying CNVs in polygenic ASD cases with unrelated subjects. For example, Girirajan et al. (2012) found that children with two CNVs not known to be pathological were eight times more likely to be diagnosed with developmental delay than controls. In the same year, a study of SHANK2 pathogenic variants found abnormalities in both individuals with neuropsychiatric disease and controls, suggesting the presence of additional variants in order to cause disease. Three of the patients with de novo SHANK2 mutations were also found to have deletions of CHRNA7 and cytoplasmic FMR1 interacting protein 1 (CYFIP1) - both previously implicated in ASD - supporting a "multiple-hit" model of autism (Leblond et al., 2012). CHRNA7 was also suggested as a potential modifier in an earlier study by Szafranski et al. (2010). Barber et al. (2013) provided further support for a multiple-loci model of ASD upon finding that patients with 16p12.1 duplications had a more severe phenotype when a second large CNV was present. Included in these hypothesized modifier regions were genes $\mathrm{G}$ protein regulated inducer of neurite outgrowth 2 (GPRIN2) previously implicated as a modifier in the study by Artuso et al. (2011) - and steroid sulfatase (STS), which was formerly thought to be non-causative (Li et al., 2010). More recently, an analysis of 20,226 patient records revealed 19 patients with CNVs in contactin 6 (CNTN6), a gene hypothesized to be involved in neurodevelopmental disorders including ASD (Repnikova et al., 2019). The authors were not able to find any significant genotype-phenotype relationships and concluded that CNV in CNTN6 were likely benign or modifying, but not causative of disease. 
In addition to CNVs, there may be thousands of smaller pathogenic variants - such as SNPs and indels - that also modulate severity. For example, in a study of developmental delay, individuals that only carried a specific 16p12.1 microdeletion had a less severe phenotype than individuals with random second variants (Girirajan et al., 2010). One study of individuals with 22q11.2 deletion syndrome - all haploinsufficient for an mGluR network gene - found that $20 \%$ who were co-diagnosed with autism had second-hit pathogenic variants, while only $2 \%$ of $22 \mathrm{q} 11 \mathrm{DS}$ individuals without autism had second hits (Wenger et al., 2016). Bonnet-Brilhault et al. (2016) assessed a family affected with ID and ASD due to NLGN4X pathogenic variants and found that individuals with ASD - but not ID or controls - had second-hit variants in glycine receptor beta $(G R L B)$ and ankyrin 3 (ANK3). Additional evidence may exist, but GWAS and WES studies have tended to focus on causative susceptibility loci. Therefore, other variants which are not causative by themselves are not often emphasized or even reported. The emerging study of all types of genetic modifiers is a relatively recent development, and continuing advancements in sequencing technology, analyzing software, and expansion of databases should lay the framework for significant advancements in the near future.

\section{Epigenetics and the Environment}

Autism susceptibility is currently estimated to be $40-80 \%$ genetic. Environmental factors - likely acting through epigenetic regulation as the major mechanism - presumably compromise the remainder of the risk. Hundreds of potential environmental factors have been suggested to contribute to risk, such as increased parental age (especially paternal), maternal complications or infections during pregnancy, or prenatal exposure to anticonvulsants (Rasalam et al., 2005; Kong et al., 2012; O’Roak et al., 2012; Ohkawara et al., 2015). In-depth reviews of these findings can be found elsewhere (Gardener et al., 2009; Chaste and Leboyer, 2012; Liu et al., 2016; Karimi et al., 2017; Modabbernia et al., 2017; Bölte et al., 2019). In this review, we will only discuss the epigenetic modifying effects of valproic acid - an anticonvulsant - as one example of the widespread modifications that an environmental factor can induce. Valproic acid has been hypothesized to modify gene expression through histone deacetylase inhibition activity and is sometimes used to induce an autistic phenotype in animal models (Kataoka et al., 2013). Examples of its far-reaching effects include apoptotic cell death in the neocortex, decreased proliferation in the ganglionic eminence, increased homeobox A1 (HOXA1) expression, abnormal serotonergic differentiation via Achaete-Scute family BHLH transcription factor 1 (ASCL1) silencing, disrupted serotonin homeostasis in the amygdala, dendritic spine loss, reduced prefrontal dopaminergic activity, and disruption of the glutamatergic/GABAergic balance (Stodgell et al., 2006; Dufour-Rainfray et al., 2010; Kataoka et al., 2013; Wang et al., 2013; Jacob et al., 2014; Takuma et al., 2014; Hara et al., 2015; Iijima et al., 2016; Mahmood et al., 2018).

In more thorough studies of the mechanism of action, Go et al. (2012) found that rats exposed to valproic acid in utero presented enhanced proliferation of neural progenitors and delayed neurogenesis by upregulating Wnt1 expression and activating the GSK-3 $\beta / \beta$-catenin pathway, leading to macrocephaly. Another study found that valproic acid increased $\mathrm{BDNF}$ by two transcriptional mechanisms involving $\mathrm{MeCP} 2$ and tissue plasminogen activator (tPA). This increase in BDNF is proposed to alter neurite outgrowth, impairing synapse formation (Ko et al., 2018). Finally, Kolozsi et al. (2009) observed a downregulation of NLGN3 - a highly implicated autism risk gene involved in synapse formation - in both hippocampal and somatosensory cortex of valproate-exposed mice. Examples of other proposed environmentally modulated mechanisms of ASD risk exist, but the literature supporting valproic acid is an excellent example of the heterogeneous effects one environmental factor can induce. Further research is strongly needed to determine how the environment modulates ASD risk.

Clearly, epigenetics can have a profound impact on the transcriptome of an organism. Pathogenic variants in even one epigenetic-regulating gene or effects from the environment can cause widespread gene dysregulation. Epigenetic modulators can themselves be causative of disease, but they may also exacerbate or ameliorate the disease phenotype by influencing expression of risk genes. More genome-wide studies are needed to understand the common ASD epigenome, and whether certain epigenetic markings might be protective or detrimental to individuals who are genetically susceptible. In addition, more studies are needed to decipher epigenetics as a link between environmental risk factors and genetic susceptibility. There is a possibility that certain environmental factors could have protective epigenetic effects, providing potential avenues for therapy.

\section{Sex-Linked Modifiers}

It is well established that ASD affects males at much higher rates than females. The reasons for this are not yet completely clear. Some studies argue that differential expression between genders may result in an under-diagnosis of females, as males tend to present more external behavior (e.g., aggression or increased repetitive behavior) and females tend to present more internal behavior (e.g., depression and avoiding demands) (Werling and Geschwind, 2013). While this may contribute to the rates of diagnosis, other possibilities include that the female sex is protective and/or males are particularly vulnerable. This may be due to influence from hormones, genetics, or other unknown factors. The genetically heterogeneous nature of ASD makes it likely that all these elements are involved - sex bias varies drastically based on factors such as which CNVs are causative or which comorbidities are present, suggesting diverse means by which a sex bias may occur (Amiet et al., 2008; Polyak et al., 2015). Potential mechanisms of sex-specific modulation will be discussed briefly, although more thorough reviews are available elsewhere (Ferri et al., 2018).

Multiple studies argue that the female sex is protective toward ASD susceptibility (Robinson et al., 2013; Pinto et al., 2014). For example, the average mutational burden in diagnosed females is much higher than in males, suggesting that males have a lower mutational burden threshold (Jacquemont et al., 2014; Desachy et al., 2015). Another study by Robinson et al. (2013) investigated nearly 10,000 dizygotic autistic twin pairs and 


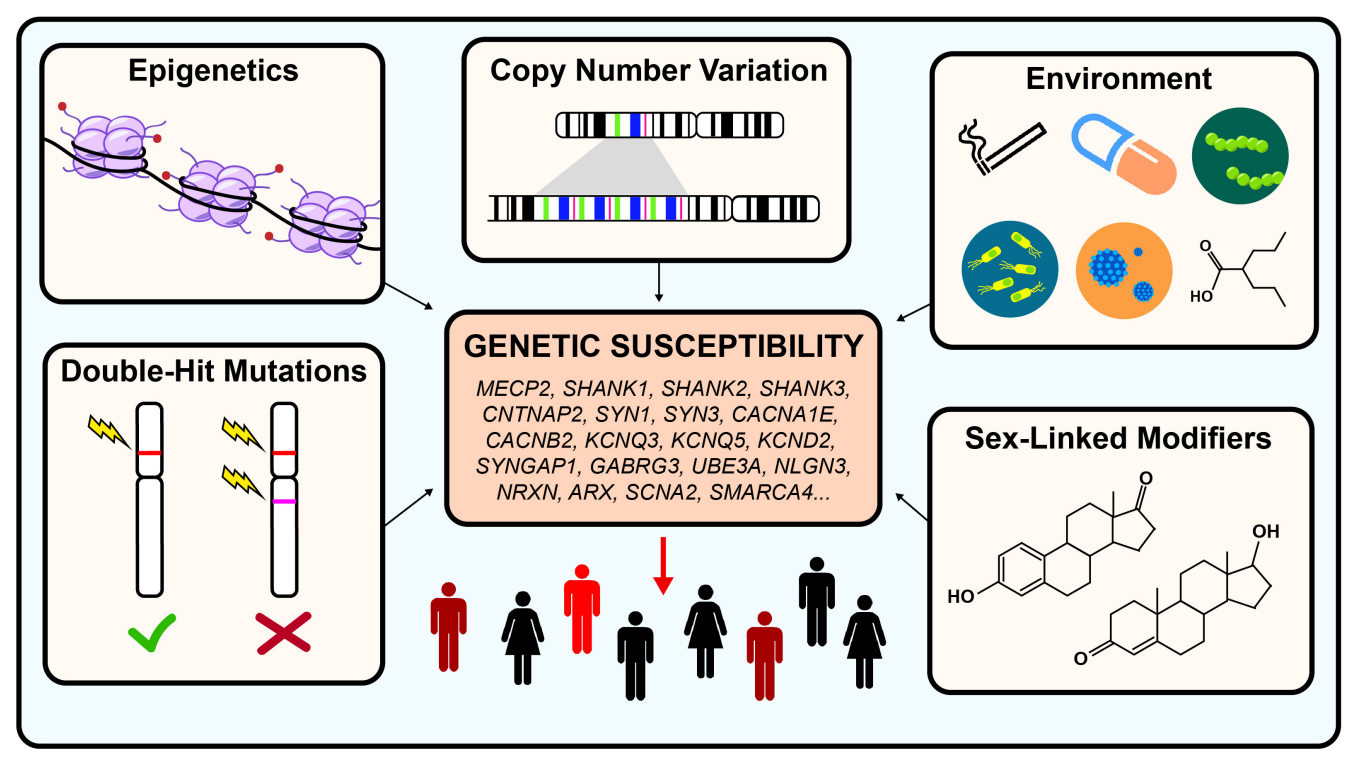

FIGURE 1 | Genetic modifiers in autism spectrum disorder. Autism is estimated to be 40-80\% heritable. However, both genetic and non-genetic factors modulate the penetrance of risk genes, resulting in a highly heterogeneous disease phenotype for similar pathogenic variants. Examples of genetic modulators include CNV, epigenetics, and double-hit mutations. Examples of non-genetic modifiers include environmental exposures and sex-linked modifiers.

found that siblings of female probands had significantly worse symptoms than siblings of male probands. Many investigations have also found that unaffected mothers may carry the same mutation as their affected male children. One particularly welldocumented example for this is the 15q11-13 duplication (Cook et al., 1997; Schroer et al., 1998; Gurrieri et al., 1999; Boyar et al., 2001). This region codes for $\mathrm{GABA}_{A}$ receptors, which is supported by the observation of perturbed GABA signaling in ASD (Al-Otaish et al., 2018). The discovery that estrogens rescue ASD phenotypes in both zebrafish and mouse models of autism is an especially convincing piece of evidence for the female protective theory (Macrì et al., 2010; Hoffman et al., 2016).

It is also possible that the female sex is not protective, but males are particularly vulnerable. Three studies of gene expression patterns noted males generally had a higher expression of genes implicated in ASD, such as chromatin regulators and genes related to immune involvement (Ziats and Rennert, 2013; Shi et al., 2016; Werling et al., 2016). A study with rat models of ASD reported male-specific downregulation of $M e C P 2$ leading to abnormal glutamate activity, providing another potential mechanism for male-specific vulnerability (Kim et al., 2016). Interestingly, multiple studies have found decreased levels of aromatase - an enzyme that catalyzes the conversion of testosterone to estradiol - in the brains of adolescent ASD individuals (Sarachana et al., 2011; Crider et al., 2014). Decreased aromatase has also been associated with decreased RAR-related orphan receptor A (RORA), an ASDassociated gene that is oppositely regulated by male and female hormones (Nguyen et al., 2010; Sarachana et al., 2011). Hu et al. (2015) found a much stronger correlation between RORA expression and that of its targets in the cortex of male mice relative to female mice, suggesting that RORA-deficient males may have greater dysregulation of genes than females.

Of course, there may also be a combination of femalespecific protective and male-specific deleterious effects. For example, Jung et al. (2018) recently assessed sexually dimorphic traits in a CHD8 $8^{+/ N 2373 K}$ mouse model of autism. While male mice demonstrated abnormal social behaviors such as isolationinduced self-grooming, female behavior was similar to controls. Neuronal excitability was also enhanced in males and suppressed in females. Transcriptomes were distinct, with female mice revealing an enrichment for ECM molecules, likely providing a protective effect.

A likely mechanism of divergent modulation is from differential effects of sex hormones, which have been hypothesized to play an important role in ASD pathology for both males and females (Baron-Cohen et al., 2005, 2015; Whitehouse et al., 2010; Honk et al., 2011; Ferri et al., 2018). For example, testosterone and estrogen have been shown to have contrasting effects on the immune system (Lenz et al., 2013; Roved et al., 2017), which has been repeatedly shown to play a pathological role in ASD (Estes and McAllister, 2015; Koyama and Ikegaya, 2015; Kim et al., 2017; McCarthy and Wright, 2017; Nadeem et al., 2019). Schwarz et al. (2011) analyzed biomarkers from individuals with Asperger's syndrome and found 24 male-specific and 17 female-specific hits, including many immune-related molecules. Spine density, another phenotype strongly implicated in autism (Comery et al., 1997; Irwin et al., 2001; Hutsler and Zhang, 2010; Durand et al., 2012; Takuma et al., 2014; Tang et al., 2014; Liu et al., 2017a,b; Soltani et al., 2017), is also affected by testosterone (Hatanaka et al., 2015). Key molecules involved in neurotransmission such as GABA, 
glutamate, serotonin, and BDNF are all implicated in ASD and modulated by sex hormones (Kim et al., 2016, p. 2; Saghazadeh and Rezaei, 2017; Al-Otaish et al., 2018; Edwards et al., 2018; Ferri et al., 2018; Garbarino et al., 2018; Zieminska et al., 2018). It is not yet clear whether the majority of differences between male and female presentation of ASD arise from differential regulatory actions of sex hormones or from other modifiers, but the presence of a sexually dimorphic phenotype is well established. Future research will likely elucidate a clearer picture of the identity and mechanisms of sex-specific modifiers.

\section{CLINICAL IMPLICATIONS AND FUTURE PERSPECTIVES}

When autism was first described, it was hypothesized to be an environmentally caused disease. Decades of research have since revealed that autism is a highly heterogeneous and extremely complex genetic condition. Even though great progress had been made in identifying hundreds of risk genes, very little is known about the different types of modifiers that may exacerbate or ameliorate disease severity. Such modifiers could include epigenetics, sex-linked modifiers, CNVs, double-hit mutations, or environmental factors (see Figure 1).

It may take many more decades of research before the scientific community has an accurate picture of how these modulators contribute to the etiology of ASD. However, this

\section{REFERENCES}

Acuna-Hidalgo, R., Bo, T., Kwint, M. P., van de Vorst, M., Pinelli, M., Veltman, J. A., et al. (2015). Post-zygotic point mutations are an underrecognized source of De Novo genomic variation. Am. J. Hum. Genet. 97, 67-74. doi: 10.1016/j. ajhg.2015.05.008

Al-Otaish, H., Al-Ayadhi, L., Bjørklund, G., Chirumbolo, S., Urbina, M. A., and El-Ansary, A. (2018). Relationship between absolute and relative ratios of glutamate, glutamine and GABA and severity of autism spectrum disorder. Metab. Brain Dis. 33, 843-854. doi: 10.1007/s11011-018-0186-6

Amiet, C., Gourfinkel-An, I., Bouzamondo, A., Tordjman, S., Baulac, M., Lechat, P., et al. (2008). Epilepsy in autism is associated with intellectual disability and gender: evidence from a meta-analysis. Biol. Psychiatry 64, 577-582. doi: 10.1016/j.biopsych.2008.04.030

Andrews, S. V., Ellis, S. E., Bakulski, K. M., Sheppard, B., Croen, L. A., HertzPicciotto, I., et al. (2017). Cross-tissue integration of genetic and epigenetic data offers insight into autism spectrum disorder. Nat. Commun. 8:1011. doi: 10.1038/s41467-017-00868-y

Artuso, R., Papa, F. T., Grillo, E., Mucciolo, M., Yasui, D. H., Dunaway, K. W., et al. (2011). Investigation of modifier genes within copy number variations in Rett syndrome. J. Hum. Genet. 56, 508-515. doi: 10.1038/jhg.2011.50

Auranen, M., Vanhala, R., Varilo, T., Ayers, K., Kempas, E., Ylisaukko-oja, T., et al. (2002). A genomewide screen for autism-spectrum disorders: evidence for a major susceptibility locus on chromosome 3q25-27. Am. J. Hum. Genet. 71, 777-790. doi: 10.1086/342720

Bae, T., Tomasini, L., Mariani, J., Zhou, B., Roychowdhury, T., Franjic, D., et al. (2018). Different mutational rates and mechanisms in human cells at pregastrulation and neurogenesis. Science 359, 550-555. doi: 10.1126/science. aan 8690

Bailey, A., Le Couteur, A., Gottesman, I., Bolton, P., Simonoff, E., Yuzda, E., et al. (1995). Autism as a strongly genetic disorder: evidence from a British twin study. Psychol. Med. 25, 63-77. doi: 10.1017/s0033291700028099 understanding is critical for the development of effective therapies. Due to the extremely diverse genetic phenotype of patients, personalized medicine may be a future avenue for maximally effective treatment. A condensed series of genetic tests - such as a microarray with identified risk loci - could be an expedient and cost-effective solution to determining genetic etiology. Alternatively, therapies may be developed to address convergent disease phenotypes that encompass multiple genetic etiologies, such as neuronal hyperexcitability and abnormal synaptic function. Autism research has come astonishingly far in just a half a century. There is much more work to be done, but continued investigation will eventually lead to a cohesive understanding of the interplay between causative genetic factors and disease modifiers in the etiology of ASD.

\section{AUTHOR CONTRIBUTIONS}

LR contributed to writing the main text and gathering all references. AG-G contributed to editing the manuscript drafts and providing insight into structure and material that should be included.

\section{FUNDING}

This work was supported by start-up funds from the Feinberg School of Medicine, Northwestern University.

Barber, J. C. K., Hall, V., Maloney, V. K., Huang, S., Roberts, A. M., Brady, A. F., et al. (2013). 16p11.2-p12.2 duplication syndrome; a genomic condition differentiated from euchromatic variation of 16p11.2. Eur. J. Hum. Genet. 21, 182-189. doi: 10.1038/ejhg.2012.144

Baron-Cohen, S., Auyeung, B., Nørgaard-Pedersen, B., Hougaard, D. M., Abdallah, M. W., Melgaard, L., et al. (2015). Elevated fetal steroidogenic activity in autism. Mol. Psychiatry 20, 369-376. doi: 10.1038/mp.2014.48

Baron-Cohen, S., Knickmeyer, R. C., and Belmonte, M. K. (2005). Sex differences in the brain: implications for explaining autism. Science 310, 819-823. doi: 10.1126/science. 1115455

Barrett, S., Beck, J. C., Bernier, R., Bisson, E., Braun, T. A., Casavant, T. L., et al. (1999). An autosomal genomic screen for autism. Collaborative linkage study of autism. Am. J. Med. Genet. 88, 609-615. doi: 10.1002/(sici)10968628(19991215)88:6<609::aid-ajmg7>3.0.co;2-1

Behnia, F., Parets, S. E., Kechichian, T., Yin, H., Dutta, E. H., Saade, G. R., et al. (2015). Fetal DNA methylation of autism spectrum disorders candidate genes: association with spontaneous preterm birth. Am. J. Obstet. Gynecol. 212:533.e1-e9. doi: 10.1016/j.ajog.2015.02.011

Blaker-Lee, A., Gupta, S., McCammon, J. M., De Rienzo, G., and Sive, H. (2012). Zebrafish homologs of genes within 16p11.2, a genomic region associated with brain disorders, are active during brain development, and include two deletion dosage sensor genes. Dis. Model. Mech. 5, 834-851. doi: 10.1242/dmm. 009944

Bölte, S., Girdler, S., and Marschik, P. B. (2019). The contribution of environmental exposure to the etiology of autism spectrum disorder. Cell. Mol. Life Sci. 76, 1275-1297. doi: 10.1007/s00018-018-2988-4

Bolton, P. F., Dennis, N. R., Browne, C. E., Thomas, N. S., Veltman, M. W. M., Thompson, R. J., et al. (2001). The phenotypic manifestations of interstitial duplications of proximal $15 \mathrm{q}$ with special reference to the autistic spectrum disorders. Am. J. Med. Genet. 105, 675-685. doi: 10.1002/ajmg.1551

Bonnet-Brilhault, F., Alirol, S., Blanc, R., Bazaud, S., Marouillat, S., Thépault, R.-A., et al. (2016). GABA/Glutamate synaptic pathways targeted by 
integrative genomic and electrophysiological explorations distinguish autism from intellectual disability. Mol. Psychiatry 21, 411-418. doi: 10.1038/mp. 2015.75

Bourdon, V., Philippe, C., Bienvenu, T., Koenig, B., Tardieu, M., Chelly, J., et al. (2001). Evidence of somatic mosaicism for a MECP2 mutation in females with Rett syndrome: diagnostic implications. J. Med. Genet. 38, 867-871. doi: $10.1136 /$ jmg.38.12.867

Boyar, F. Z., Whitney, M. M., Lossie, A. C., Gray, B. A., Keller, K. L., Stalker, H. J., et al. (2001). A family with a grand-maternally derived interstitial duplication of proximal 15q. Clin. Genet. 60, 421-430. doi: 10.1034/j.13990004.2001.600604.x

Bruder, C. E. G., Piotrowski, A., Gijsbers, A. A. C. J., Andersson, R., Erickson, S., Diaz, et al. (2008). Phenotypically concordant and discordant monozygotic twins display different DNA copy-number-variation profiles. Am. J. Hum. Genet. 82, 763-771. doi: 10.1016/j.ajhg.2007.12.011

Buxbaum, J. D., Silverman, J. M., Smith, C. J., Kilifarski, M., Reichert, J., Hollander, E., et al. (2001). Evidence for a susceptibility gene for autism on chromosome 2 and for genetic heterogeneity. Am. J. Hum. Genet. 68, 1514-1520. doi: 10.1086/ 320588

Carney, R. M., Wolpert, C. M., Ravan, S. A., Shahbazian, M., Ashley-Koch, A., Cuccaro, M. L., et al. (2003). Identification of MeCP2 mutations in a series of females with autistic disorder. Pediatr. Neurol. 28, 205-211. doi: 10.1016/s08878994(02)00624-0

Casanova, E. L., Sharp, J. L., Chakraborty, H., Sumi, N. S., and Casanova, M. F. (2016). Genes with high penetrance for syndromic and non-syndromic autism typically function within the nucleus and regulate gene expression. Mol. Autism 7:18. doi: 10.1186/s13229-016-0082-z

Castermans, D., Thienpont, B., Volders, K., Crepel, A., Vermeesch, J. R., Schrander-Stumpel, C. T., et al. (2008). Position effect leading to haploinsufficiency in a mosaic ring chromosome 14 in a boy with autism. Eur. J. Hum. Genet. 16, 1187-1192. doi: 10.1038/ejhg.2008.71

Chao, H.-T., Zoghbi, H. Y., and Rosenmund, C. (2007). MeCP2 controls excitatory synaptic strength by regulating glutamatergic synapse number. Neuron 56, 58-65. doi: 10.1016/j.neuron.2007.08.018

Chaste, P., and Leboyer, M. (2012). Autism risk factors: genes, environment, and gene-environment interactions. Dialogues Clin. Neurosci. 14, 281-292.

Cheng, T.-L., and Qiu, Z. (2014). MeCP2: multifaceted roles in gene regulation and neural development. Neurosci. Bull. 30, 601-609. doi: 10.1007/s12264-0141452-6

Clayton-Smith, J., Watson, P., Ramsden, S., and Black, G. (2000). Somatic mutation in MECP2 as a non-fatal neurodevelopmental disorder in males. Lancet 356, 830-832. doi: 10.1016/S0140-6736(00)02661-1

Comery, T. A., Harris, J. B., Willems, P. J., Oostra, B. A., Irwin, S. A., Weiler, I. J., et al. (1997). Abnormal dendritic spines in fragile X knockout mice: maturation and pruning deficits. Proc. Natl. Acad. Sci. U.S.A. 94, 5401-5404. doi: 10.1073/pnas.94.10.5401

Constantino, J. N., Zhang, Y., Frazier, T., Abbacchi, A. M., and Law, P. (2010). Sibling recurrence and the genetic epidemiology of autism. Am. J. Psychiatry 167, 1349-1356. doi: 10.1176/appi.ajp.2010.09101470

Cook, E. H., Lindgren, V., Leventhal, B. L., Courchesne, R., Lincoln, A., Shulman, C., et al. (1997). Autism or atypical autism in maternally but not paternally derived proximal $15 \mathrm{q}$ duplication. Am. J. Hum. Genet. 60, 928-934.

Crider, A., Thakkar, R., Ahmed, A. O., and Pillai, A. (2014). Dysregulation of estrogen receptor beta (ER $\beta)$, aromatase (CYP19A1), and ER co-activators in the middle frontal gyrus of autism spectrum disorder subjects. Mol. Autism 5:46. doi: 10.1186/2040-2392-5-46

Cross-Disorder Group of the Psychiatric Genomics Consortium (2013). Identification of risk loci with shared effects on five major psychiatric disorders: a genome-wide analysis. Lancet 381, 1371-1379. doi: 10.1016/S0140-6736(12)62129-1

Cross-Disorder Group of the Psychiatric Genomics Consortium, Lee, S. H., Ripke, S., Neale, B. M., Faraone, S. V., Purcell, S. M., et al. (2013). Genetic relationship between five psychiatric disorders estimated from genome-wide SNPs. Nat. Genet. 45, 984-994. doi: 10.1038/ng.2711

De Rubeis, S., He, X., Goldberg, A. P., Poultney, C. S., Samocha, K., Cicek, A. E., et al. (2014). Synaptic, transcriptional and chromatin genes disrupted in autism. Nature 515, 209-215. doi: 10.1038/nature13772
Desachy, G., Croen, L. A., Torres, A. R., Kharrazi, M., Delorenze, G. N., Windham, G. C., et al. (2015). Increased female autosomal burden of rare copy number variants in human populations and in autism families. Mol. Psychiatry 20, 170-175. doi: 10.1038/mp.2014.179

D'Gama, A. M., and Walsh, C. A. (2018). Somatic mosaicism and neurodevelopmental disease. Nat. Neurosci. 21, 1504-1514. doi: 10.1038/s41593-018-0257-3

Dou, Y., Yang, X., Li, Z., Wang, S., Zhang, Z., Ye, A. Y., et al. (2017). Postzygotic single-nucleotide mosaicisms contribute to the etiology of autism spectrum disorder and autistic traits and the origin of mutations. Hum. Mutat. 38, 1002-1013. doi: 10.1002/humu.23255

Doyle, G. A., Crist, R. C., Karatas, E. T., Hammond, M. J., Ewing, A. D., Ferraro, T. N., et al. (2017). Analysis of LINE-1 elements in DNA from postmortem brains of individuals with Schizophrenia. Neuropsychopharmacology 42, 26022611. doi: 10.1038/npp.2017.115

Duffney, L. J., Valdez, P., Tremblay, M. W., Cao, X., Montgomery, S., McConkieRosell, A., et al. (2018). Epigenetics and autism spectrum disorder: a report of an autism case with mutation in $\mathrm{H} 1$ linker histone HIST1H1E and literature review. Am. J. Med. Genet. B Neuropsychiatr. Genet. 177, 426-433. doi: 10.1002/ ajmg.b.32631

Dufour-Rainfray, D., Vourc'h, P., Le Guisquet, A.-M., Garreau, L., Ternant, D., Bodard, S., et al. (2010). Behavior and serotonergic disorders in rats exposed prenatally to valproate: a model for autism. Neurosci. Lett. 470, 55-59. doi: 10.1016/j.neulet.2009.12.054

Durand, C. M., Perroy, J., Loll, F., Perrais, D., Fagni, L., Bourgeron, T., et al. (2012). SHANK3 mutations identified in autism lead to modification of dendritic spine morphology via an actin-dependent mechanism. Mol. Psychiatry 17, 71-84. doi: 10.1038/mp.2011.57

Edwards, K. A., Madden, A. M. K., and Zup, S. L. (2018). Serotonin receptor regulation as a potential mechanism for sexually dimorphic oxytocin dysregulation in a model of Autism. Brain Res. 1701, 85-92. doi: 10.1016/j. brainres.2018.07.020

Escamilla, C. O., Filonova, I., Walker, A. K., Xuan, Z. X., Holehonnur, R., Espinosa, F., et al. (2017). Kctd13 deletion reduces synaptic transmission via increased RhoA. Nature 551, 227-231. doi: 10.1038/nature24470

Estes, M. L., and McAllister, A. K. (2015). Immune mediators in the brain and peripheral tissues in autism spectrum disorder. Nat. Rev. Neurosci. 16, 469-486. doi: $10.1038 / \mathrm{nrn} 3978$

Ferri, S. L., Abel, T., and Brodkin, E. S. (2018). Sex differences in autism spectrum disorder: a review. Curr. Psychiatry Rep. 20:9. doi: 10.1007/s11920-018-0874-2

Fisher, E., and Scambler, P. (1994). Human haploinsufficiency - one for sorrow, two for joy. Nat. Genet. 7, 5-7. doi: 10.1038/ng0594-5

Folstein, S., and Rutter, M. (1977). Genetic influences and infantile autism. Nature 265, 726-728. doi: 10.1038/265726a0

Freed, D., and Pevsner, J. (2016). The contribution of mosaic variants to autism spectrum disorder. PLoS Genet. 12:e1006245. doi: 10.1371/journal.pgen. 1006245

Garbarino, V. R., Gilman, T. L., Daws, L. C., and Gould, G. G. (2018). Extreme enhancement or depletion of serotonin transporter function and serotonin availability in autism spectrum disorder. Pharmacol. Res. 140, 85-99. doi: 10. 1016/j.phrs.2018.07.010

Gardener, H., Spiegelman, D., and Buka, S. L. (2009). Prenatal risk factors for autism: a comprehensive meta-analysis. Br. J. Psychiatry J. Ment. Sci. 195, 7-14. doi: 10.1192/bjp.bp.108.051672

Geschwind, D. H. (2011). Genetics of autism spectrum disorders. Trends Cogn. Sci. 15, 409-416. doi: 10.1016/j.tics.2011.07.003

Gilissen, C., Hehir-Kwa, J. Y., Thung, D. T., van de Vorst, M., van Bon, B. W. M., Willemsen, M. H., et al. (2014). Genome sequencing identifies major causes of severe intellectual disability. Nature 511, 344-347. doi: 10.1038/nature 13394

Gillberg, C., and Wahlström, J. (1985). Chromosome abnormalities in infantile autism and other childhood psychoses: a population study of 66 cases. Dev. Med. Child Neurol. 27, 293-304. doi: 10.1111/j.1469-8749.1985.tb04539.x

Giovedí, S., Corradi, A., Fassio, A., and Benfenati, F. (2014). Involvement of synaptic genes in the pathogenesis of autism spectrum disorders: the case of synapsins. Front. Pediatr. 2:94. doi: 10.3389/fped.2014.00094

Girirajan, S., Dennis, M. Y., Baker, C., Malig, M., Coe, B. P., Campbell, C. D., et al. (2013). Refinement and discovery of new hotspots of copy-number variation 
associated with autism spectrum disorder. Am. J. Hum. Genet. 92, 221-237. doi: 10.1016/j.ajhg.2012.12.016

Girirajan, S., Rosenfeld, J. A., Coe, B. P., Parikh, S., Friedman, N., Goldstein, A., et al. (2012). Phenotypic heterogeneity of genomic disorders and rare copy-number variants. N. Engl. J. Med. 367, 1321-1331. doi: 10.1056/ NEJMoa1200395

Girirajan, S., Rosenfeld, J. A., Cooper, G. M., Antonacci, F., Siswara, P., Itsara, A., et al. (2010). A recurrent 16p12.1 microdeletion supports a two-hit model for severe developmental delay. Nat. Genet. 42, 203-209. doi: 10.1038/ng.534

Glessner, J. T., Li, J., Wang, D., March, M., Lima, L., Desai, A., et al. (2017). Copy number variation meta-analysis reveals a novel duplication at 9p24 associated with multiple neurodevelopmental disorders. Genome Med. 9:106. doi: 10.1186/ s13073-017-0494-1

Glessner, J. T., Wang, K., Cai, G., Korvatska, O., Kim, C. E., Wood, S., et al. (2009). Autism genome-wide copy number variation reveals ubiquitin and neuronal genes. Nature 459, 569-573. doi: 10.1038/nature 07953

Go, H. S., Kim, K. C., Choi, C. S., Jeon, S. J., Kwon, K. J., Han, S.-H., et al. (2012). Prenatal exposure to valproic acid increases the neural progenitor cell pool and induces macrocephaly in rat brain via a mechanism involving the GSK-3 $\beta / \beta$-catenin pathway. Neuropharmacology 63, 1028-1041. doi: 10.1016/ j.neuropharm.2012.07.028

Golzio, C., Willer, J., Talkowski, M. E., Oh, E. C., Taniguchi, Y., Jacquemont, S., et al. (2012). KCTD13 is a major driver of mirrored neuroanatomical phenotypes of the 16p11.2 copy number variant. Nature 485, 363-367. doi: 10.1038/nature11091

Guffanti, G., Lievers, L. S., Bonati, M. T., Marchi, M., Geronazzo, L., Nardocci, N., et al. (2011). Role of UBE3A and ATP10A genes in autism susceptibility region 15q11-q13 in an Italian population: a positive replication for UBE3A. Psychiatry Res. 185, 33-38. doi: 10.1016/j.psychres.2010.04.057

Gurrieri, F., Battaglia, A., Torrisi, L., Tancredi, R., Cavallaro, C., Sangiorgi, E., et al. (1999). Pervasive developmental disorder and epilepsy due to maternally derived duplication of 15q11-q13. Neurology 52, 1694-1697.

Hamilton, A. M., Oh, W. C., Vega-Ramirez, H., Stein, I. S., Hell, J. W., Patrick, G. N., et al. (2012). Activity-dependent growth of new dendritic spines is regulated by the proteasome. Neuron 74, 1023-1030. doi: 10.1016/j.neuron. 2012.04.031

Hara, Y., Takuma, K., Takano, E., Katashiba, K., Taruta, A., Higashino, K., et al. (2015). Reduced prefrontal dopaminergic activity in valproic acid-treated mouse autism model. Behav. Brain Res. 289, 39-47. doi: 10.1016/j.bbr.2015. 04.022

Hatanaka, Y., Wada, K., and Kabuta, T. (2015). Abnormal instability, excess density, and aberrant morphology of dendritic spines in prenatally testosteroneexposed mice. Neurochem. Int. 85-86, 53-58. doi: 10.1016/j.neuint.2015. 04.008

Havlovicova, M., Novotna, D., Kocarek, E., Novotna, K., Bendova, S., Petrak, B., et al. (2007). A girl with neurofibromatosis type 1, atypical autism and mosaic ring chromosome 17. Am. J. Med. Genet. A 143A, 76-81. doi: 10.1002/ajmg.a. 31569

Hoffman, E. J., Turner, K. J., Fernandez, J. M., Cifuentes, D., Ghosh, M., Ijaz, S., et al. (2016). Estrogens suppress a behavioral phenotype in Zebrafish mutants of the autism risk gene, CNTNAP2. Neuron 89, 725-733. doi: 10.1016/j.neuron. 2015.12.039

Horev, G., Ellegood, J., Lerch, J. P., Son, Y.-E. E., Muthuswamy, L., Vogel, H., et al. (2011). Dosage-dependent phenotypes in models of 16p11.2 lesions found in autism. Proc. Natl. Acad. Sci. U.S.A. 108, 17076-17081. doi: 10.1073/pnas. 1114042108

Hu, V. W., Sarachana, T., Sherrard, R. M., and Kocher, K. M. (2015). Investigation of sex differences in the expression of RORA and its transcriptional targets in the brain as a potential contributor to the sex bias in autism. Mol. Autism 6:7. doi: 10.1186/2040-2392-6-7

Hutsler, J. J., and Zhang, H. (2010). Increased dendritic spine densities on cortical projection neurons in autism spectrum disorders. Brain Res. 1309, 83-94. doi: 10.1016/j.brainres.2009.09.120

Iijima, Y., Behr, K., Iijima, T., Biemans, B., Bischofberger, J., and Scheiffele, P. (2016). Distinct defects in synaptic differentiation of neocortical neurons in response to prenatal valproate exposure. Sci. Rep. 6:27400. doi: 10.1038/ srep 27400
IMGSAC (1998). Full genome screen for autism with evidence for linkage to a region on chromosome $7 \mathrm{q} \mid$ human molecular genetics $\mid$ oxford academic. Hum. Mol. Genet. 7, 571-578. doi: 10.1093/hmg/7.3.571

International Molecular Genetic Study of Autism Consortium [IMGSAC] (2001). A genomewide screen for autism: strong evidence for linkage to chromosomes 2q, 7q, and 16p. Am. J. Hum. Genet. 69, 570-581. doi: 10.1086/323264

Iossifov, I., O’Roak, B. J., Sanders, S. J., Ronemus, M., Krumm, N., Levy, D., et al. (2014). The contribution of de novo coding mutations to autism spectrum disorder. Nature 515, 216-221. doi: 10.1038/nature13908

Irwin, S. A., Patel, B., Idupulapati, M., Harris, J. B., Crisostomo, R. A., Larsen, B. P., et al. (2001). Abnormal dendritic spine characteristics in the temporal and visual cortices of patients with fragile-X syndrome: a quantitative examination. Am. J. Med. Genet. 98, 161-167. doi: 10.1002/1096-8628(20010115)98:2<161: AID-AJMG1025<3.0.CO;2-B

Iyer, J., Singh, M. D., Jensen, M., Patel, P., Pizzo, L., Huber, E., et al. (2018). Pervasive genetic interactions modulate neurodevelopmental defects of the autism-associated 16p11.2 deletion in Drosophila melanogaster. Nat. Commun. 9:2548. doi: 10.1038/s41467-018-04882-6

Jacob, J., Ribes, V., Moore, S., Constable, S. C., Sasai, N., Gerety, S. S., et al. (2014). Valproic acid silencing of ascl1b/Ascl1 results in the failure of serotonergic differentiation in a zebrafish model of fetal valproate syndrome. Dis. Model. Mech. 7, 107-117. doi: 10.1242/dmm.013219

Jacquemont, S., Coe, B. P., Hersch, M., Duyzend, M. H., Krumm, N., Bergmann, S., et al. (2014). A higher mutational burden in females supports a "female protective model" in neurodevelopmental disorders. Am. J. Hum. Genet. 94, 415-425. doi: 10.1016/j.ajhg.2014.02.001

Jamain, S., Quach, H., Betancur, C., Råstam, M., Colineaux, C., Gillberg, I. C., et al. (2003). Mutations of the X-linked genes encoding neuroligins NLGN3 and NLGN4 are associated with autism. Nat. Genet. 34, 27-29. doi: 10.1038/ng1136

James, S. J., Shpyleva, S., Melnyk, S., Pavliv, O., and Pogribny, I. P. (2013). Complex epigenetic regulation of Engrailed-2 (EN-2) homeobox gene in the autism cerebellum. Transl. Psychiatry 3:e232. doi: 10.1038/tp.2013.8

Jiang, Y.-H., Sahoo, T., Michaelis, R. C., Bercovich, D., Bressler, J., Kashork, C. D., et al. (2004). A mixed epigenetic/genetic model for oligogenic inheritance of autism with a limited role for UBE3A. Am. J. Med. Genet. A 131, 1-10. doi: 10.1002/ajmg.a.30297

Jung, H., Park, H., Choi, Y., Kang, H., Lee, E., Kweon, H., et al. (2018). Sexually dimorphic behavior, neuronal activity, and gene expression in Chd8-mutant mice. Nat. Neurosci. 21, 1218-1228. doi: 10.1038/s41593-018-0208-z

Kakinuma, H., Ozaki, M., Sato, H., and Takahashi, H. (2008). Variation in GABAA subunit gene copy number in an autistic patient with mosaic $4 \mathrm{p}$ duplication (p12p16). Am. J. Med. Genet. B Neuropsychiatr. Genet. 147B, 973-975. doi: 10.1002/ajmg.b.30663

Kalsner, L., and Chamberlain, S. J. (2015). Prader-Willi, Angelman, and 15q11-q13 duplication syndromes. Pediatr. Clin. North Am. 62, 587-606. doi: 10.1016/j. pcl.2015.03.004

Kanner, L. (1943). Autistic disturbances of affective contact. Nerv. Child 2, 217-250.

Karimi, P., Kamali, E., Mousavi, S. M., and Karahmadi, M. (2017). Environmental factors influencing the risk of autism. J. Res. Med. Sci. 22:27. doi: 10.4103/17351995.200272

Kataoka, S., Takuma, K., Hara, Y., Maeda, Y., Ago, Y., and Matsuda, T. (2013). Autism-like behaviours with transient histone hyperacetylation in mice treated prenatally with valproic acid. Int. J. Neuropsychopharmacol. 16, 91-103. doi: 10.1017/S1461145711001714

Khanzada, N. S., Butler, M. G., and Manzardo, A. M. (2017). GeneAnalytics pathway analysis and genetic overlap among autism spectrum disorder, bipolar disorder and schizophrenia. Int. J. Mol. Sci. 18:E527. doi: 10.3390/ijms18030527

Kim, H.-J., Cho, M.-H., Shim, W. H., Kim, J. K., Jeon, E.-Y., Kim, D.-H., et al. (2017). Deficient autophagy in microglia impairs synaptic pruning and causes social behavioral defects. Mol. Psychiatry 22, 1576-1584. doi: 10.1038/mp. 2016.103

Kim, K. C., Choi, C. S., Kim, J.-W., Han, S.-H., Cheong, J. H., Ryu, J. H., et al. (2016). MeCP2 modulates sex differences in the postsynaptic development of the valproate animal model of autism. Mol. Neurobiol. 53, 40-56. doi: 10.1007/ s12035-014-8987-z

Knudson, A. G. (1971). Mutation and cancer: statistical study of retinoblastoma. PNAS 68, 820-823. doi: 10.1073/pnas.68.4.820 
Ko, H. M., Jin, Y., Park, H. H., Lee, J. H., Jung, S. H., Choi, S. Y., et al. (2018). Dual mechanisms for the regulation of brain-derived neurotrophic factor by valproic acid in neural progenitor cells. Korean J. Physiol. Pharmacol. 22, 679-688. doi: 10.4196/kjpp.2018.22.6.679

Kolozsi, E., Mackenzie, R. N., Roullet, F. I., deCatanzaro, D., and Foster, J. A. (2009). Prenatal exposure to valproic acid leads to reduced expression of synaptic adhesion molecule neuroligin 3 in mice. Neuroscience 163, 1201-1210. doi: 10.1016/j.neuroscience.2009.07.021

Kong, A., Frigge, M. L., Masson, G., Besenbacher, S., Sulem, P., Magnusson, G., et al. (2012). Rate of de novo mutations and the importance of father's age to disease risk. Nature 488, 471-475. doi: 10.1038/nature11396

Korb, E., Herre, M., Zucker-Scharff, I., Gresack, J., Allis, C. D., and Darnell, R. B. (2017). Excess translation of epigenetic regulators contributes to fragile $\mathrm{X}$ syndrome and is alleviated by Brd4 inhibition. Cell 170, 1209.e20-1223.e20. doi: 10.1016/j.cell.2017.07.033

Koyama, R., and Ikegaya, Y. (2015). Microglia in the pathogenesis of autism spectrum disorders. Neurosci. Res. 100, 1-5. doi: 10.1016/j.neures.2015.06.005

Krebs, M. O., Betancur, C., Leroy, S., Bourdel, M. C., Gillberg, C., Leboyer, M., et al. (2002). Absence of association between a polymorphic GGC repeat in the 5 ' untranslated region of the reelin gene and autism. Mol. Psychiatry 7, 801-804. doi: 10.1038/sj.mp.4001071

Krupp, D. R., Barnard, R. A., Duffourd, Y., Evans, S. A., Mulqueen, R. M., Bernier, R., et al. (2017). Exonic mosaic mutations contribute risk for autism spectrum disorder. Am. J. Hum. Genet. 101, 369-390. doi: 10.1016/j.ajhg.2017.07.016

Kubota, T., and Mochizuki, K. (2016). Epigenetic effect of environmental factors on autism spectrum disorders. Int. J. Environ. Res. Public. Health 13:E504. doi: 10.3390/ijerph13050504

Kumar, R. A., KaraMohamed, S., Sudi, J., Conrad, D. F., Brune, C., Badner, J. A., et al. (2008). Recurrent 16p11.2 microdeletions in autism. Hum. Mol. Genet. 17, 628-638. doi: 10.1093/hmg/ddm376

Kunio, M., Yang, C., Minakuchi, Y., Ohori, K., Soutome, M., Hirasawa, T., et al. (2013). Comparison of genomic and epigenomic expression in monozygotic twins discordant for rett syndrome. PLoS One 8:e66729. doi: 10.1371/journal. pone.0066729

Ladd-Acosta, C., Hansen, K. D., Briem, E., Fallin, M. D., Kaufmann, W. E., and Feinberg, A. P. (2014). Common DNA methylation alterations in multiple brain regions in autism. Mol. Psychiatry 19, 862-871. doi: 10.1038/mp.2013.114

Lai, M.-C., Lombardo, M. V., and Baron-Cohen, S. (2014). Autism. Lancet 383, 896-910. doi: 10.1016/S0140-6736(13)61539-1

Lamb, J. A., Parr, J. R., Bailey, A. J., and Monaco, A. P. (2002). Autism. NeuroMol. Med. 2, 11-28. doi: 10.1385/NMM:2:1:11

Leblond, C. S., Heinrich, J., Delorme, R., Proepper, C., Betancur, C., Huguet, G., et al. (2012). Genetic and functional analyses of SHANK2 mutations suggest a multiple hit model of autism spectrum disorders. PLoS Genet. 8:e1002521. doi: 10.1371/journal.pgen.1002521

Lee, S. Y., Ramirez, J., Franco, M., Lectez, B., Gonzalez, M., Barrio, R., et al. (2014). Ube3a, the E3 ubiquitin ligase causing Angelman syndrome and linked to autism, regulates protein homeostasis through the proteasomal shuttle Rpn10. Cell. Mol. Life Sci. 71, 2747-2758. doi: 10.1007/s00018-013-1526-7

Lenz, K. M., Nugent, B. M., Haliyur, R., and McCarthy, M. M. (2013). Microglia are essential to masculinization of brain and behavior. J. Neurosci. 33, 2761-2772. doi: 10.1523/JNEUROSCI.1268-12.2013

Li, F., Shen, Y., Köhler, U., Sharkey, F. H., Menon, D., Coulleaux, L., et al. (2010). Interstitial microduplication of Xp22.31: causative of intellectual disability or benign copy number variant? Eur. J. Med. Genet. 53, 93-99. doi: 10.1016/j.ejmg. 2010.01.004

Lim, E. T., Uddin, M., De Rubeis, S., Chan, Y., Kamumbu, A. S., Zhang, X., et al. (2017). Rates, distribution and implications of postzygotic mosaic mutations in autism spectrum disorder. Nat. Neurosci. 20, 1217-1224. doi: 10.1038/nn.4598

Liu, J., Nyholt, D. R., Magnussen, P., Parano, E., Pavone, P., Geschwind, D., et al. (2001). A genomewide screen for autism susceptibility loci. Am. J. Hum. Genet. 69, 327-340. doi: 10.1086/321980

Liu, S., Zhou, L., Yuan, H., Vieira, M., Sanz-Clemente, A., Badger, J. D., et al. (2017a). A rare variant identified within the GluN2B C-Terminus in a patient with autism affects NMDA receptor surface expression and spine density. J. Neurosci. 37, 4093-4102. doi: 10.1523/JNEUROSCI.0827-16.2017

Liu, X., Campanac, E., Cheung, H.-H., Ziats, M. N., Canterel-Thouennon, L., Raygada, M., et al. (2017b). Idiopathic autism: cellular and molecular phenotypes in pluripotent stem cell-derived neurons. Mol. Neurobiol. 54, 4507-4523. doi: 10.1007/s12035-016-9961-8

Liu, Z., Li, X., Zhang, J.-T., Cai, Y.-J., Cheng, T.-L., Cheng, C., et al. (2016). Autism-like behaviours and germline transmission in transgenic monkeys overexpressing MeCP2. Nature 530, 98-102. doi: 10.1038/nature 16533

Loomes, R., Hull, L., and Mandy, W. P. L. (2017). What is the male-to-female ratio in autism spectrum disorder? A systematic review and meta-analysis. J. Am. Acad. Child Adolesc. Psychiatry 56, 466-474. doi: 10.1016/j.jaac.2017. 03.013

Macrì, S., Biamonte, F., Romano, E., Marino, R., Keller, F., and Laviola, G. (2010). Perseverative responding and neuroanatomical alterations in adult heterozygous reeler mice are mitigated by neonatal estrogen administration. Psychoneuroendocrinology 35, 1374-1387. doi: 10.1016/j.psyneuen.2010. 03.012

Mahmood, U., Ahn, S., Yang, E.-J., Choi, M., Kim, H., Regan, P., et al. (2018). Dendritic spine anomalies and PTEN alterations in a mouse model of VPAinduced autism spectrum disorder. Pharmacol. Res. 128, 110-121. doi: 10.1016/ j.phrs.2017.08.006

Marshall, C. R., Noor, A., Vincent, J. B., Lionel, A. C., Feuk, L., Skaug, J., et al. (2008). Structural variation of chromosomes in autism spectrum disorder. Am. J. Hum. Genet. 82, 477-488. doi: 10.1016/j.ajhg.2007.12.009

Marshall, C. R., and Scherer, S. W. (2012). Detection and characterization of copy number variation in autism spectrum disorder. Methods Mol. Biol. 838, 115-135. doi: 10.1007/978-1-61779-507-7_5

Martin, J., Cooper, M., Hamshere, M. L., Pocklington, A., Scherer, S. W., Kent, L., et al. (2014). Biological overlap of attention-deficit/hyperactivity disorder and autism spectrum disorder: evidence from copy number variants. J. Am. Acad. Child Adolesc. Psychiatry 53, 761.e26-770.e26. doi: 10.1016/j.jaac.2014. 03.004

McCallion, A. S., Stames, E., Conlon, R. A., and Chakravarti, A. (2003). Phenotype variation in two-locus mouse models of Hirschsprung disease: tissue-specific interaction between Ret and Ednrb. PNAS 100, 1826-1831. doi: 10.1073/pnas. 0337540100

McCarthy, M. M., and Wright, C. L. (2017). Convergence of sex differences and the neuroimmune system in autism spectrum disorder. Biol. Psychiatry 81, 402-410. doi: 10.1016/j.biopsych.2016.10.004

McCarthy, S. E., Gillis, J., Kramer, M., Lihm, J., Yoon, S., Berstein, Y., et al. (2014). De novo mutations in schizophrenia implicate chromatin remodeling and support a genetic overlap with autism and intellectual disability. Mol. Psychiatry 19, 652-658. doi: 10.1038/mp.2014.29

Michaelson, J. J., Shin, M.-K., Koh, J.-Y., Brueggeman, L., Zhang, A., Katzman, A., et al. (2017). Neuronal PAS domain proteins 1 and 3 are master regulators of neuropsychiatric risk genes. Biol. Psychiatry 82, 213-223. doi: 10.1016/j. biopsych.2017.03.021

Modabbernia, A., Velthorst, E., and Reichenberg, A. (2017). Environmental risk factors for autism: an evidence-based review of systematic reviews and metaanalyses. Mol. Autism 8:13. doi: 10.1186/s13229-017-0121-4

Mor, M., Nardone, S., Sams, D. S., and Elliott, E. (2015). Hypomethylation of miR142 promoter and upregulation of microRNAs that target the oxytocin receptor gene in the autism prefrontal cortex. Mol. Autism 6:46. doi: 10.1186/s13229015-0040-1

Mulligan, A., Anney, R. J. L., O’Regan, M., Chen, W., Butler, L., Fitzgerald, M., et al. (2009). Autism symptoms in attention-deficit/hyperactivity disorder: a familial trait which correlates with conduct, oppositional defiant, language and motor disorders. J. Autism Dev. Disord. 39, 197-209. doi: 10.1007/s10803-0080621-3

Nadeem, A., Ahmad, S. F., Attia, S. M., Al-Ayadhi, L. Y., Al-Harbi, N. O., and Bakheet, S. A. (2019). Dysregulated enzymatic antioxidant network in peripheral neutrophils and monocytes in children with autism. Prog. Neuropsychopharmacol. Biol. Psychiatry 88, 352-359. doi: 10.1016/j.pnpbp. 2018.08.020

Nagarajan, R. P., Hogart, A. R., Gwye, Y., Martin, M. R., and LaSalle, J. M. (2006). Reduced MeCP2 expression is frequent in autism frontal cortex and correlates with aberrant MECP2 promoter methylation. Epigenetics 1, e1-e11.

Nagarajan, R. P., Patzel, K. A., Martin, M., Yasui, D. H., Swanberg, S. E., HertzPicciotto, I., et al. (2008). MECP2 promoter methylation and X chromosome inactivation in autism. Autism Res. 1, 169-178. doi: 10.1002/aur.24 
Nardone, S., and Elliott, E. (2016). The interaction between the immune system and epigenetics in the etiology of autism spectrum disorders. Front. Neurosci. 10:329. doi: 10.3389/fnins.2016.00329

Nguyen, A., Rauch, T. A., Pfeifer, G. P., and Hu, V. W. (2010). Global methylation profiling of lymphoblastoid cell lines reveals epigenetic contributions to autism spectrum disorders and a novel autism candidate gene, RORA, whose protein product is reduced in autistic brain. FASEB J. 24, 3036-3051. doi: 10.1096/fj.10154484

Nijmeijer, J. S., Arias-Vásquez, A., Rommelse, N. N. J., Altink, M. E., Anney, R. J. L., Asherson, P., et al. (2010). Identifying loci for the overlap between attention-deficit/hyperactivity disorder and autism spectrum disorder using a genome-wide QTL linkage approach. J. Am. Acad. Child Adolesc. Psychiatry 49, 675-685. doi: 10.1016/j.jaac.2010.03.015

Ohkawara, T., Katsuyama, T., Ida-Eto, M., Narita, N., and Narita, M. (2015). Maternal viral infection during pregnancy impairs development of fetal serotonergic neurons. Brain Dev. 37, 88-93. doi: 10.1016/j.braindev.2014. 03.007

Oliveira, G., Matoso, E., Vicente, A., Ribeiro, P., Marques, C., Ataíde, A., et al. (2003). Partial tetrasomy of chromosome $3 \mathrm{q}$ and mosaicism in a child with autism. J. Autism Dev. Disord. 33, 177-185.

O’Roak, B. J., Vives, L., Girirajan, S., Karakoc, E., Krumm, N., Coe, B. P., et al. (2012). Sporadic autism exomes reveal a highly interconnected protein network of de novo mutations. Nature 485, 246-250. doi: 10.1038/nature10989

Papanikolaou, K., Paliokosta, E., Gyftodimou, J., Kolaitis, G., Vgenopoulou, S., Sarri, C., et al. (2006). A case of partial trisomy of chromosome 8p associated with autism. J. Autism Dev. Disord. 36, 705-709. doi: 10.1007/s10803-0060104-3

Persico, A. M., D’Agruma, L., Maiorano, N., Totaro, A., Militerni, R., Bravaccio, C., et al. (2001). Reelin gene alleles and haplotypes as a factor predisposing to autistic disorder. Mol. Psychiatry 6, 150-159. doi: 10.1038/sj.mp.4000850

Peters, S. U., Beaudet, A. L., Madduri, N., and Bacino, C. A. (2004). Autism in Angelman syndrome: implications for autism research. Clin. Genet. 66, 530-536. doi: 10.1111/j.1399-0004.2004.00362.x

Pinto, D., Delaby, E., Merico, D., Barbosa, M., Merikangas, A., Klei, L., et al. (2014). Convergence of genes and cellular pathways dysregulated in autism spectrum disorders. Am. J. Hum. Genet. 94, 677-694. doi: 10.1016/j.ajhg.2014.03.018

Pinto, D., Pagnamenta, A. T., Klei, L., Anney, R., Merico, D., Regan, R., et al. (2010). Functional impact of global rare copy number variation in autism spectrum disorders. Nature 466, 368-372. doi: 10.1038/nature09146

Pizzo, L., Jensen, M., Polyak, A., Rosenfeld, J. A., Mannik, K., Krishnan, A., et al. (2019). Rare variants in the genetic background modulate cognitive and developmental phenotypes in individuals carrying disease-associated variants. Genet. Med. 21, 816-825. doi: 10.1038/s41436-018-0266-3

Poduri, A., Evrony, G. D., Cai, X., and Walsh, C. A. (2013). Somatic mutation, genomic variation, and neurological disease. Science 341:1237758. doi: 10.1126/ science. 1237758

Polyak, A., Rosenfeld, J. A., and Girirajan, S. (2015). An assessment of sex bias in neurodevelopmental disorders. Genome Med. 7:94. doi: 10.1186/s13073-0150216-215

Pucilowska, J., Vithayathil, J., Tavares, E. J., Kelly, C., Karlo, J. C., and Landreth, G. E. (2015). The 16p11.2 deletion mouse model of autism exhibits altered cortical progenitor proliferation and brain cytoarchitecture linked to the ERK MAPK pathway. J. Neurosci. 35, 3190-3200. doi: 10.1523/JNEUROSCI.486413.2015

Puram, S. V., Kim, A. H., Park, H.-Y., Anckar, J., and Bonni, A. (2013). The ubiquitin receptor S5a/Rpn10 links centrosomal proteasomes with dendrite development in the mammalian brain. Cell Rep. 4, 19-30. doi: 10.1016/j.celrep. 2013.06.006

Qin, L., Ma, K., Wang, Z.-J., Hu, Z., Matas, E., Wei, J., et al. (2018). Social deficits in Shank3-deficient mouse models of autism are rescued by histone deacetylase (HDAC) inhibition. Nat. Neurosci. 21, 564-575. doi: 10.1038/s41593-0180110-8

Qin, W., Chan, J. A., Vinters, H. V., Mathern, G. W., Franz, D. N., Taillon, B. E., et al. (2010). Analysis of TSC cortical tubers by deep sequencing of TSC1, TSC2, and KRAS demonstrates that small second hit mutations in these genes are rare events. Brain Pathol. Zurich Switz 20, 1096-1105. doi: 10.1111/j.1750-3639. 2010.00416.x
Rapoport, J., Chavez, A., Greenstein, D., Addington, A., and Gogtay, N. (2009). Autism spectrum disorders and childhood-onset schizophrenia: clinical and biological contributions to a relation revisited. J. Am. Acad. Child Adolesc. Psychiatry 48, 10-18. doi: 10.1097/CHI.0b013e31818b1c63

Rasalam, A. D., Hailey, H., Williams, J. H. G., Moore, S. J., Turnpenny, P. D., Lloyd, D. J., et al. (2005). Characteristics of fetal anticonvulsant syndrome associated autistic disorder. Dev. Med. Child Neurol. 47, 551-555. doi: 10.1017/ s0012162205001076

Rasia-Filho, A. A., Londero, R. G., and Achaval, M. (2000). Functional activities of the amygdala: an overview. J. Psychiatry Neurosci. 25, 14-23.

Reiersen, A. M., Constantino, J. N., Volk, H. E., and Todd, R. D. (2007). Autistic traits in a population-based ADHD twin sample. J. Child Psychol. Psychiatry 48, 464-472. doi: 10.1111/j.1469-7610.2006.01720.x

Repnikova, E. A., Lyalin, D. A., McDonald, K., Astbury, C., Hansen-Kiss, E., Cooley, L. D., et al. (2019). CNTN6 copy number variations: uncertain clinical significance in individuals with neurodevelopmental disorders. Eur. J. Med. Genet. doi: 10.1016/j.ejmg.2019.02.008 [Epub ahead of print].

Rio, M., Royer, G., Gobin, S., de Blois, M., Ozilou, C., Bernheim, A., et al. (2013). Monozygotic twins discordant for submicroscopic chromosomal anomalies in 2p25.3 region detected by array CGH. Clin. Genet. 84, 31-36. doi: 10.1111/cge. 12036

Risch, N., Hoffmann, T. J., Anderson, M., Croen, L. A., Grether, J. K., and Windham, G. C. (2014). Familial recurrence of autism spectrum disorder: evaluating genetic and environmental contributions. Am. J. Psychiatry 171, 1206-1213. doi: 10.1176/appi.ajp.2014.13101359

Robinson, E. B., Lichtenstein, P., Anckarsäter, H., Happé, F., and Ronald, A. (2013). Examining and interpreting the female protective effect against autistic behavior. Proc. Natl. Acad. Sci. U.S.A. 110, 5258-5262. doi: 10.1073/pnas. 1211070110

Rommelse, N. N. J., Franke, B., Geurts, H. M., Hartman, C. A., and Buitelaar, J. K. (2010). Shared heritability of attention-deficit/hyperactivity disorder and autism spectrum disorder. Eur. Child Adolesc. Psychiatry 19, 281-295. doi: 10.1007/s00787-010-0092-x

Ronald, A., Simonoff, E., Kuntsi, J., Asherson, P., and Plomin, R. (2008). Evidence for overlapping genetic influences on autistic and ADHD behaviours in a community twin sample. J. Child Psychol. Psychiatry 49, 535-542. doi: 10.1111/ j.1469-7610.2007.01857.x

Ronemus, M., Iossifov, I., Levy, D., and Wigler, M. (2014). The role of de novo mutations in the genetics of autism spectrum disorders. Nat. Rev. Genet. 15, 133-141. doi: 10.1038/nrg3585

Roved, J., Westerdahl, H., and Hasselquist, D. (2017). Sex differences in immune responses: hormonal effects, antagonistic selection, and evolutionary consequences. Horm. Behav. 88, 95-105. doi: 10.1016/j.yhbeh.2016.11.017

Saghazadeh, A., and Rezaei, N. (2017). Brain-derived neurotrophic factor levels in autism: a systematic review and meta-analysis. J. Autism Dev. Disord. 47, 1018-1029. doi: 10.1007/s10803-016-3024-x

Samaco, R. C., Hogart, A., and LaSalle, J. M. (2005). Epigenetic overlap in autismspectrum neurodevelopmental disorders: MECP2 deficiency causes reduced expression of UBE3A and GABRB3. Hum. Mol. Genet. 14, 483-492. doi: 10. 1093/hmg/ddi045

Sandin, S., Lichtenstein, P., Kuja-Halkola, R., Larsson, H., Hultman, C. M., and Reichenberg, A. (2014). The familial risk of autism. JAMA 311, 1770-1777. doi: 10.1001/jama.2014.4144

Sarachana, T., Xu, M., Wu, R.-C., and Hu, V. W. (2011). Sex hormones in autism: androgens and estrogens differentially and reciprocally regulate RORA, a novel candidate gene for autism. PLoS One 6:e17116. doi: 10.1371/journal.pone. 0017116

Sauter, S., von Beust, G., Burfeind, P., Weise, A., Starke, H., Liehr, T., et al. (2003). Autistic disorder and chromosomal mosaicism 46,XY[123]/46,XY,del(20)(pter $->$ p12.2)[10]. Am. J. Med. Genet. A 120A, 533-536. doi: 10.1002/ajmg.a.20089

Schmunk, G., and Gargus, J. J. (2013). Channelopathy pathogenesis in autism spectrum disorders. Front. Genet. 4:222. doi: 10.3389/fgene.2013.00222

Schork, A. J., Won, H., Appadurai, V., Nudel, R., Gandal, M., Delaneau, O., et al. (2019). A genome-wide association study of shared risk across psychiatric disorders implicates gene regulation during fetal neurodevelopment. Nat. Neurosci. 22, 353-361. doi: 10.1038/s41593-018-0320-0 
Schroer, R. J., Phelan, M. C., Michaelis, R. C., Crawford, E. C., Skinner, S. A., Cuccaro, M., et al. (1998). Autism and maternally derived aberrations of chromosome 15q. Am. J. Med. Genet. 76, 327-336. doi: 10.1002/(sici)10968628(19980401)76:4<327::aid-ajmg8>3.0.co;2-m

Schwarz, E., Guest, P. C., Rahmoune, H., Wang, L., Levin, Y., Ingudomnukul, E., et al. (2011). Sex-specific serum biomarker patterns in adults with Asperger's syndrome. Mol. Psychiatry 16, 1213-1220. doi: 10.1038/mp.2010.102

Sebat, J., Lakshmi, B., Malhotra, D., Troge, J., Lese-Martin, C., Walsh, T., et al. (2007). Strong association of De Novo copy number mutations with autism. Science 316, 445-449. doi: 10.1126/science.1138659

Serajee, F., Nabi, R., Zhong, H., and Mahbubul, H. (2003). Association of INPP1, PIK3CG, and TSC2 gene variants with autistic disorder: implications for phosphatidylinositol signalling in autism. J. Med. Genet. 40:e119. doi: 10.1136/ jmg.40.11.e119

Shao, Y., Cuccaro, M. L., Hauser, E. R., Raiford, K. L., Menold, M. M., Wolpert, C. M., et al. (2003). Fine mapping of autistic disorder to chromosome 15q11q13 by use of phenotypic subtypes. Am. J. Hum. Genet. 72, 539-548. doi: $10.1086 / 367846$

Shi, L., Zhang, Z., and Su, B. (2016). Sex biased gene expression profiling of human brains at major developmental stages. Sci. Rep. 6:21181. doi: 10.1038/srep21181

Short, P. J., McRae, J. F., Gallone, G., Sifrim, A., Won, H., Geschwind, D. H., et al. (2018). De novo mutations in regulatory elements in neurodevelopmental disorders. Nature 555, 611-616. doi: 10.1038/nature25983

Smith, S. E. P., Zhou, Y.-D., Zhang, G., Jin, Z., Stoppel, D. C., and Anderson, M. P. (2011). Increased gene dosage of ube3a results in autism traits and decreased glutamate synaptic transmission in mice. Sci. Transl. Med. 3:103ra97. doi: $10.1126 /$ scitranslmed.3002627

Soltani, A., Lebrun, S., Carpentier, G., Zunino, G., Chantepie, S., Maïza, A., et al. (2017). Increased signaling by the autism-related Engrailed-2 protein enhances dendritic branching and spine density, alters synaptic structural matching, and exaggerates protein synthesis. PLoS One 12:e181350. doi: 10.1371/journal. pone. 0181350

Stamouli, S., Anderlid, B.-M., Willfors, C., Thiruvahindrapuram, B., Wei, J., Berggren, S., et al. (2018). Copy number variation analysis of 100 twin pairs enriched for neurodevelopmental disorders. Twin Res. Hum. Genet. 21, 1-11. doi: 10.1017/thg.2017.69

Stefansson, H., Meyer-Lindenberg, A., Steinberg, S., Magnusdottir, B., Morgen, K., Arnarsdottir, S., et al. (2014). CNVs conferring risk of autism or schizophrenia affect cognition in controls. Nature 505, 361-366. doi: 10.1038/nature12818

Stergiakouli, E., Davey Smith, G., Martin, J., Skuse, D. H., Viechtbauer, W., Ring, S. M., et al. (2017). Shared genetic influences between dimensional ASD and ADHD symptoms during child and adolescent development. Mol. Autism 8:18. doi: 10.1186/s13229-017-0131-2

Stern, D., Cho, M. T., Chikarmane, R., Willaert, R., Retterer, K., Kendall, F., et al. (2017). Association of the missense variant p.Arg203Trp in PACS1 as a cause of intellectual disability and seizures. Clin. Genet. 92, 221-223. doi: 10.1111/cge. 12956

Stessman, H. A. F., Xiong, B., Coe, B. P., Wang, T., Hoekzema, K., Fenckova, M., et al. (2017). Targeted sequencing identifies 91 neurodevelopmental disorder risk genes with autism and developmental disability biases. Nat. Genet. 49, 515-526. doi: 10.1038/ng.3792

Stodgell, C. J., Ingram, J. L., O'Bara, M., Tisdale, B. K., Nau, H., and Rodier, P. M. (2006). Induction of the homeotic gene Hoxal through valproic acid's teratogenic mechanism of action. Neurotoxicol. Teratol. 28, 617-624. doi: 10. 1016/j.ntt.2006.08.004

Strømme, P., Mangelsdorf, M. E., Scheffer, I. E., and Gécz, J. (2002). Infantile spasms, dystonia, and other X-linked phenotypes caused by mutations in Aristaless related homeobox gene, ARX. Brain Dev. 24, 266-268. doi: 10.1016/ s0387-7604(02)00079-7

Sullivan, P. F., Magnusson, C., Reichenberg, A., Boman, M., Dalman, C., Davidson, M., et al. (2012). Family history of schizophrenia and bipolar disorder as risk factors for autism. Arch. Gen. Psychiatry 69, 1099-1103. doi: 10.1001/ archgenpsychiatry.2012.730

Sun, W., Poschmann, J., Cruz-Herrera del Rosario, R., Parikshak, N. N., Hajan, H. S., Kumar, V., et al. (2016). Histone acetylome-wide association study of autism spectrum disorder. Cell 167, 1385.e11-1397.e11. doi: 10.1016/j.cell.2016. 10.031
Szafranski, P., Schaaf, C. P., Person, R. E., Gibson, I. B., Xia, Z., Mahadevan, S., et al. (2010). Structures and molecular mechanisms for common $15 q 13.3$ Microduplications involving CHRNA7: benign or pathological? Hum. Mutat. 31, 840-850. doi: $10.1002 /$ humu.21284

Takuma, K., Hara, Y., Kataoka, S., Kawanai, T., Maeda, Y., Watanabe, R., et al. (2014). Chronic treatment with valproic acid or sodium butyrate attenuates novel object recognition deficits and hippocampal dendritic spine loss in a mouse model of autism. Pharmacol. Biochem. Behav. 126, 43-49. doi: 10.1016/ j.pbb.2014.08.013

Talebizadeh, Z., Bittel, D., Miles, J., Takahashi, N., Wang, C., Kibiryeva, N., et al. (2002). No association between HOXA1 and HOXB1 genes and autism spectrum disorders (ASD). J. Med. Genet. 39:e70. doi: 10.1136/jmg.39.11.e70

Tang, G., Gudsnuk, K., Kuo, S.-H., Cotrina, M. L., Rosoklija, G., Sosunov, A., et al. (2014). Loss of mTOR-dependent macroautophagy causes autistic-like synaptic pruning deficits. Neuron 83, 1131-1143. doi: 10.1016/j.neuron.2014.07.040

Thapar, A., and Cooper, M. (2013). Copy number variation: what is it and what has it told us about child psychiatric disorders? J. Am. Acad. Child Adolesc. Psychiatry 52, 772-774. doi: 10.1016/j.jaac.2013.05.013

The Autism Genome Project Consortium, P., Paterson, A. D., Zwaigenbaum, L., Roberts, W., Brian, J., et al. (2007). Mapping autism risk loci using genetic linkage and chromosomal rearrangements. Nat. Genet. 39, 319-328. doi: 10. 1038/ng1985

The Autism Spectrum Disorders Working Group of The Psychiatric Genomics Consortium (2017). Meta-analysis of GWAS of over 16,000 individuals with autism spectrum disorder highlights a novel locus at 10q24.32 and a significant overlap with schizophrenia. Mol. Autism 8:21. doi: 10.1186/s13229-017-0137-9

Tran, S. S., Jun, H.-I., Bahn, J. H., Azghadi, A., Ramaswami, G., Van Nostrand, E. L., et al. (2019). Widespread RNA editing dysregulation in brains from autistic individuals. Nat. Neurosci. 22, 25-36. doi: 10.1038/s41593-018-0287-x

Turner, T. N., Coe, B. P., Dickel, D. E., Hoekzema, K., Nelson, B. J., Zody, M. C., et al. (2017). Genomic patterns of de novo mutation in simplex autism. Cell 171, 710.e12-722.e12. doi: 10.1016/j.cell.2017.08.047

Turner, T. N., Hormozdiari, F., Duyzend, M. H., McClymont, S. A., Hook, P. W., Iossifov, I., et al. (2016). Genome sequencing of autism-affected families reveals disruption of putative noncoding regulatory DNA. Am. J. Hum. Genet. 98, 58-74. doi: 10.1016/j.ajhg.2015.11.023

Tyburczy, M. E., Jozwiak, S., Malinowska, I. A., Chekaluk, Y., Pugh, T. J., Wu, C.L., et al. (2015). A shower of second hit events as the cause of multifocal renal cell carcinoma in tuberous sclerosis complex. Hum. Mol. Genet. 24, 1836-1842. doi: $10.1093 / \mathrm{hmg} / \mathrm{ddu} 597$

Honk, J., Schutter, D. J., Bos, P. A., Kruijt, A.-W., Lentjes, E. G., and Baron-Cohen, S. (2011). Testosterone administration impairs cognitive empathy in women depending on second-to-fourth digit ratio. Proc. Natl. Acad. Sci. U.S.A. 108, 3448-3452. doi: 10.1073/pnas.1011891108

Vorstman, J., van Daalen, E., Jalali, G., Schmidt, E., Pasterkamp, R., de Jonge, M., et al. (2011). A double hit implicates DIAPH3 as an autism risk gene. Mol. Psychiatry 16, 442-451. doi: 10.1038/mp.2010.26

Wang, C.-C., Lin, H.-C., Chan, Y.-H., Gean, P.-W., Yang, Y. K., and Chen, P. S. (2013). 5-HT1A-receptor agonist modified amygdala activity and amygdalaassociated social behavior in a valproate-induced rat autism model. Int. J. Neuropsychopharmacol. 16, 2027-2039. doi: 10.1017/S1461145713000473

Wang, W., Corominas, R., and Lin, G. N. (2019). De novo mutations from whole exome sequencing in neurodevelopmental and psychiatric disorders: from discovery to application. Front. Genet. 10:258. doi: 10.3389/fgene.2019.00258

Weiss, L. A., Shen, Y., Korn, J. M., Arking, D. E., Miller, D. T., Fossdal, R., et al. (2008). Association between microdeletion and microduplication at $16 \mathrm{p} 11.2$ and Autism. N. Engl. J. Med. 358, 667-675. doi: 10.1056/NEJMoa075974

Wenger, T. L., Kao, C., McDonald-McGinn, D. M., Zackai, E. H., Bailey, A., Schultz, R. T., et al. (2016). The role of mGluR copy number variation in genetic and environmental forms of syndromic autism spectrum disorder. Sci. Rep. 6:19372. doi: $10.1038 /$ srep 19372

Werling, D. M., and Geschwind, D. H. (2013). Sex differences in autism spectrum disorders. Curr. Opin. Neurol. 26, 146-153. doi: 10.1097/WCO. 0b013e32835ee548

Werling, D. M., Parikshak, N. N., and Geschwind, D. H. (2016). Gene expression in human brain implicates sexually dimorphic pathways in autism spectrum disorders. Nat. Commun. 7:10717. doi: 10.1038/ncomms10717 
Whitehouse, A. J. O., Maybery, M. T., Hart, R., Mattes, E., Newnham, J. P., Sloboda, D. M., et al. (2010). Fetal androgen exposure and pragmatic language ability of girls in middle childhood: implications for the extreme male-brain theory of autism. Psychoneuroendocrinology 35, 1259-1264. doi: 10.1016/j.psyneuen. 2010.02.007

Williams, C. A., Driscoll, D. J., and Dagli, A. I. (2010). Clinical and genetic aspects of Angelman syndrome. Genet. Med. 12, 385-395. doi: 10.1097/GIM. 0b013e3181def138

Wong, C. C. Y., Meaburn, E. L., Ronald, A., Price, T. S., Jeffries, A. R., Schalkwyk, L. C., et al. (2014). Methylomic analysis of monozygotic twins discordant for autism spectrum disorder and related behavioural traits. Mol. Psychiatry 19, 495-503. doi: 10.1038/mp.2013.41

Woodbury-Smith, M., and Scherer, S. W. (2018). Progress in the genetics of autism spectrum disorder. Dev. Med. Child Neurol. 60, 445-451. doi: 10.1111/dmcn. 13717

Xu, X., Li, C., Gao, X., Xia, K., Guo, H., Li, Y., et al. (2018). Excessive UBE3A dosage impairs retinoic acid signaling and synaptic plasticity in autism spectrum disorders. Cell Res. 28, 48-68. doi: 10.1038/cr.2017.132

Yi, J. J., Berrios, J., Newbern, J. M., Snider, W. D., Philpot, B. D., Hahn, K. M., et al. (2015). An autism-linked mutation disables phosphorylation control of UBE3A. Cell 162, 795-807. doi: 10.1016/j.cell.2015. 06.045

Yi, J. J., Paranjape, S. R., Walker, M. P., Choudhury, R., Wolter, J. M., Fragola, G., et al. (2017). The autism-linked UBE3A T485A mutant E3 ubiquitin ligase activates the $\mathrm{Wnt} / \beta$-catenin pathway by inhibiting the proteasome. J. Biol. Chem. 292, 12503-12515. doi: 10.1074/jbc.M117. 788448

Yurov, Y. B., Vorsanova, S. G., Iourov, I. Y., Demidova, I. A., Beresheva, A. K., Kravetz, V. S., et al. (2007). Unexplained autism is frequently associated with low-level mosaic aneuploidy. J. Med. Genet. 44, 521-525. doi: 10.1136/jmg.2007. 049312

Zeldovich, L. (2018). The Evolution of 'Autism' as a Diagnosis, Explained. Available at: https://www.spectrumnews.org/news/evolution-autism-diagnosisexplained/(accessed December 4, 2018).

Zhang, H., Liu, X., Zhang, C., Mundo, E., Macciardi, F., Grayson, D. R., et al. (2002). Reelin gene alleles and susceptibility to autism spectrum disorders. Mol. Psychiatry 7, 1012-1017. doi: 10.1038/sj.mp.4001124

Zhubi, A., Chen, Y., Guidotti, A., and Grayson, D. (2017). Epigenetic regulation of RELN and GAD1 in the frontal cortex (FC) of autism spectrum disorder (ASD) subjects. Int. J. Dev. Neurosci. 62, 63-72. doi: 10.1016/j.ijdevneu.2017.02.003

Ziats, M. N., and Rennert, O. M. (2013). Sex-biased gene expression in the developing brain: implications for autism spectrum disorders. Mol. Autism 4:10. doi: 10.1186/2040-2392-4-10

Zieminska, E., Toczylowska, B., Diamandakis, D., Hilgier, W., Filipkowski, R. K., Polowy, R., et al. (2018). Glutamate, glutamine and GABA levels in rat brain measured using MRS, HPLC and NMR methods in study of two models of autism. Front. Mol. Neurosci. 11:418. doi: 10.3389/fnmol.2018.00418

Conflict of Interest Statement: The authors declare that the research was conducted in the absence of any commercial or financial relationships that could be construed as a potential conflict of interest.

Copyright (c) 2019 Rylaarsdam and Guemez-Gamboa. This is an open-access article distributed under the terms of the Creative Commons Attribution License (CC BY). The use, distribution or reproduction in other forums is permitted, provided the original author(s) and the copyright owner(s) are credited and that the original publication in this journal is cited, in accordance with accepted academic practice. No use, distribution or reproduction is permitted which does not comply with these terms. 